\title{
Mechanisms of Efferent-Mediated Responses in the Turtle Posterior Crista
}

\author{
Joseph C. Holt, ${ }^{1}$ Anna Lysakowski, ${ }^{2}$ and Jay M. Goldberg ${ }^{1}$ \\ ${ }^{1}$ Department of Neurobiology, Pharmacology, and Physiology, University of Chicago, Chicago, Illinois 60637, and 2Department of Anatomy and Cell \\ Biology, University of Illinois at Chicago, Chicago, Illinois 60612
}

To study the cellular mechanisms of efferent actions, we recorded from vestibular-nerve afferents close to the turtle posterior crista while efferent fibers were electrically stimulated. Efferent-mediated responses were obtained from calyx-bearing $(\mathrm{CD}$, calyx and dimorphic) afferents and from bouton (B) afferents distinguished by their neuroepithelial locations into BT units near the torus and BM units at intermediate sites. The spike discharge of CD units is strongly excited by efferent stimulation, whereas BT and BM units are inhibited, with BM units also showing a postinhibitory excitation. Synaptic activity was recorded intracellularly after spikes were blocked. Responses of BT/BM units to single efferent shocks consist of a brief depolarization followed by a prolonged hyperpolarization. Both components reflect variations in hair-cell quantal release rates and are eliminated by pharmacological antagonists of $\alpha 9 / \alpha 10$ nicotinic receptors. Blocking calcium-dependent SK potassium channels converts the biphasic response into a prolonged depolarization. Results can be explained, as in other hair-cell systems, by the sequential activation of $\alpha 9 / \alpha 10$ and SK channels. In BM units, the postinhibitory excitation is based on an increased rate of hair-cell quanta and depends on the preceding inhibition. There is, in addition, an efferentmediated, direct depolarization of BT/BM and CD fibers. In CD units, it is the exclusive efferent response. Nicotinic antagonists have different effects on hair-cell efferent actions and on the direct depolarization of $\mathrm{CD}$ and BT/BM units. Ultrastructural studies, besides confirming the efferent innervation of type II hair cells and calyx endings, show that turtle efferents commonly contact afferent boutons terminating on type II hair cells.

Key words: vestibular afferent; vestibular efferent; hair cell; nicotinic; $\alpha 9$; pharmacology

\section{Introduction}

Almost all hair-cell organs receive an efferent innervation originating in the brainstem and terminating on hair cells and afferent processes (Warr and Guinan, 1979; Meredith, 1988; Lysakowski and Goldberg, 2004). In auditory (Furukawa, 1981; Art et al., 1985; Fuchs and Murrow, 1992; Oliver et al., 2000), vibratory (Sugai et al., 1991) and lateral-line (Russell, 1968; Dawkins et al., 2005) receptors, efferents inhibit afferent discharge. Efferentmediated responses in vestibular organs are more diverse, consisting of excitation (mammals, Goldberg and Fernandez, 1980; toadfish, Boyle and Highstein, 1990) or excitation and inhibition in different afferents (frog, Rossi et al., 1980; turtle, Brichta and Goldberg, 2000b; pigeon, Dickman and Correia, 1993).

The major efferent neurotransmitter is acetylcholine (ACh) (Guth et al., 1998). To account for the diversity of responses in vestibular organs based on the actions of ACh would require differences in cholinergic receptors or in subsequent intracellular

\footnotetext{
Received April 11, 2006; revised 0ct. 12, 2006; accepted Nov. 6, 2006.

This work was supported by National Institutes of Health Grant DC 02058 (J.M.G.) and Training Grant DC 00058 (J.C.H.). We are grateful for the expert technical assistance of Steven Price. Suggestions on previous versions of this manuscript were made by Drs. Aaron Fox, Ruth Anne Eatock, Galen Kaufman, Golda Anne Kevetter, Peggy Mason, and Daniel McGehee.

Correspondence should be addressed to Joseph C. Holt at his present address: Department of Otolaryngology, University of Texas Medical Branch, 7.102 Medical Research Building, 301 University Boulevard, Galveston, TX 77555-1063. E-mail: jcholt@utmb.edu.

DOI:10.1523/JNEUROSCI.3539-06.2006

Copyright $\odot 2006$ Society for Neuroscience $\quad$ 0270-6474/06/2613180-14\$15.00/0
}

signaling mechanisms. Inhibition in nonvestibular organs has been explained by the activation of hair-cell $\alpha 9 / \alpha 10$ nicotinic acetylcholine receptors (nAChRs) (Elgoyhen et al., 2001), allowing the influx of $\mathrm{Ca}^{2+}$ ions (Weisstaub et al., 2002) and the subsequent opening of calcium-activated SK potassium channels (Oliver et al., 2000). In comparison, although we know a great deal about efferent effects on spike discharge in vestibular organs (Goldberg et al., 1999), studies of the corresponding cellular mechanisms have been limited. Afferent recordings show that efferent excitation and inhibition in frog vestibular organs (Rossi et al., 1980; Sugai et al., 1991), as well as inhibition in the toadfish lagena (Locke et al., 1999), are correlated with changes in quantal rate arising from hair cells. Inhibition in the frog saccular macula, a vibratory organ, is consistent with the sequential activation of $\alpha 9 / \alpha 10$ and SK channels (Sugai et al., 1992; Holt et al., 2001; Rothlin et al., 2003). Studies done in the frog posterior crista, a more typical vestibular organ as it monitors head movements, indicate that multiple nicotinic receptors are involved, but a more precise identification has not been made (Guth et al., 1998; Holt et al., 2003). Other topics requiring additional study in vestibular organs are the roles of $\alpha 9 / \alpha 10$ and SK in efferent inhibition and the mechanisms responsible for efferent excitation, including the postinhibitory excitation seen in the efferent responses of some afferents and the prolonged excitatory efferent actions seen in other afferents (Rossi and Martini, 1991; Brichta and Goldberg, 2000b). 
In this paper, responses to electrical stimulation of efferent fibers were recorded from turtle posterior crista afferents near their termination in the neuroepithelium. The goals were (1) to describe the synaptic activity responsible for the various responses, (2) to determine the contributions of efferent synapses on hair cells and afferent fibers, and (3) to identify potential neurotransmitter receptor(s) and intracellular signaling mechanisms.

\section{Materials and Methods}

Tissue preparation. Red-eared turtles (Trachemys scripta elegans, 100-300 g, 7-14 cm carapace length) of either sex were decapitated, and the head was split parasagittally. Most of the skull and brain on the left side was retained. The specimen was placed in an oxygenated control solution (in mM): $105 \mathrm{NaCl}, 4 \mathrm{KCl}, 0.8 \mathrm{MgCl}_{2}, 2 \mathrm{CaCl}_{2}, 25 \mathrm{NaHCO}_{3}, 2 \mathrm{Na}$-pyruvate, 10 glucose, $\mathrm{pH} 7.2-7.3$ after bubbling with $95 \% \mathrm{O}_{2} / 5 \% \mathrm{CO}_{2}$. Experiments were conducted at room temperature $\left(21-23^{\circ} \mathrm{C}\right)$. All procedures were approved by the Institutional Animal Care and Use Committee of the University of Chicago.

To expose the posterior ampullary nerve for recording, the half-brain was blocked transversely between the levels of the trigeminal and glossopharyngeal nerves. The bony channels containing the glossopharyngeal and vagal nerves were opened. The two nerves were removed, exposing the bone directly over the posterior ampulla. A fenestra was made, revealing the ampullary nerve, including the separate branches to the two hemicristae. Connective tissue covering the nerve was removed with a fine tungsten hook.

Recording setup. After being mounted in a recording chamber on its lateral surface, the half-head was viewed with a dissecting microscope. The posterior ampullary nerve was superfused with the oxygenated control solution from a gravity-fed pipette capable of delivering solutions at 3-4 $\mu \mathrm{l} / \mathrm{s}$ from any one of four $10 \mathrm{ml}$ reservoirs.

Glass microelectrodes filled with $3 \mathrm{M} \mathrm{KCl}$ were connected to a preamplifier (Biomedical Engineering, Thornwood, NY), which neutralized microelectrode capacitance by driving the shield of the input cable. Impedances were typically $40-80 \mathrm{M} \Omega$. Microelectrodes were advanced in 5 $\mu \mathrm{m}$ steps with a Burleigh Inchworm drive mounted on a three-axis micromanipulator (EXFO Burleigh Products Group, Victor, NY). Recordings were made from the posterior ampullary nerve just as it bifurcates to innervate the two hemicristae. The recording site was $\sim 250 \mu \mathrm{m}$ from the neuroepithelium, a distance estimated to be just over one-quarter of a length constant (Holt et al., 2006).

Electrical stimulation of efferent fibers was used to classify afferents (Holt et al., 2006). All efferent fibers destined for the posterior crista, but none of its afferents, travel in the so-called cross-bridge, a nerve bundle running between the anterior and posterior divisions of the VIIIth nerve (Fayyazuddin et al., 1991). The cross-bridge was exposed by removing a small section of the roof of the mouth, immediately rostral to the bony protuberance housing the lagena. To avoid muscle contractions during stimulation, jaw muscles were removed and the facial nerve was severed as it passed into the middle ear. Stimulating electrodes were silver wires (AG10T; Medwire, Mt. Vernon, NY), insulated except for their $0.5 \mathrm{~mm}$ chlorided tips. One electrode was placed on the cross-bridge; a second electrode was placed on nearby bone. Electrical stimuli consisted of trains of $100 \mu$ s constant-current shocks delivered from a stimulus isolator (model A360; World Precision Instruments, Sarasota, FL) to the two electrodes. The cross-bridge electrode was the cathode.

Quantal analysis. Many efferent effects are exerted on hair cells and only indirectly affect quantal activity in the afferent nerve fiber. As has been described (Neher and Sakaba 2003; Holt et al., 2006), we used shot-noise theory to characterize such activity. The key assumptions of the theory, which have been verified (Holt et al., 2006), are that the shapes of individual quantal events are stereotyped and their timing is governed by Poisson statistics. According to Rice's (1944) extension of Campbell's theorem, the mean $\left(\lambda_{1}\right)$, variance $\left(\lambda_{2}\right)$, and the third central moment or skew $\left(\lambda_{3}\right)$ are related to the quantal rate (qrate, $\xi$ ), quantal size (qsize, $h$ ), and the shape of individual quanta $[f(t), t \geq 0]$ by the following:

$$
\begin{aligned}
& \lambda_{1}=\xi\langle h\rangle I_{1} \\
& \lambda_{2}=\xi\left\langle h^{2}\right\rangle I_{2} \\
& \lambda_{3}=\xi\left\langle h^{3}\right\rangle I_{3},
\end{aligned}
$$

where the angle brackets indicate expected values. Here and elsewhere, superscripts are exponents, and subscripts are indices. $I_{1}, I_{2}$, and $I_{3}$ are integrals of the following form:

$$
I_{n}=\int_{0}^{\infty} f^{n}(t) d t,
$$

and $f(t)$ is normalized to a peak value of unity.

Note that the strict application of the equations requires stationary rates and sizes and can be applied equally well to time and ensemble averages meeting these conditions. In this paper, we mainly used ensemble averages, which are more useful under the nonstationary conditions obtaining during efferent responses. Ensemble means $\left(\lambda_{1}\right)$ were evaluated from the original records, whereas ensemble variances $\left(\lambda_{2}\right)$ and skews $\left(\lambda_{3}\right)$ were calculated after the records had been digitally high-pass filtered (single-pole, corner frequency of $1000 \mathrm{rad} / \mathrm{s}=159 \mathrm{~Hz}$ ). When filtered data are used, $f(t)$ in Equation 2 has to be normalized before filtering.

In calculating the variance, it is necessary to subtract instrumental (residual) noise, which is defined as the noise remaining after quanta are silenced as indicated by $\lambda_{3}=0$. This was done for each impalement. Details of the calculations were presented by Holt et al. (2006). Another contribution to the variance, channel noise, was disregarded because it was shown in the aforementioned paper to be small compared with synaptic noise. The ratio of quantal variance to the residual variance determines the accuracy of the estimates. In our case, the ratio is typically $10-15$, much larger than the value of unity, at which the accuracy begins to fail.

To investigate whether a response can be attributed to a variation in qrate or qsize, we plotted the relationship between $\lambda_{3}$ and $\lambda_{2}$. Specifically, a qrate variation leads to a linear relationship:

$$
\lambda_{3}=\frac{D_{3} I_{3}\langle h\rangle}{D_{2} I_{2}} \lambda_{2}
$$

whereas a qsize variation, other parameters remaining the same, gives a nonlinear relationship:

$$
\lambda_{3}^{2}=\frac{\left(D_{3} I_{3}\right)^{2}}{\xi\left(D_{2} I_{2}\right)^{3}} \lambda_{2}^{3},
$$

i.e., $\lambda_{3}$ is proportional to $\lambda_{2}^{3 / 2}$. $D_{2}$ and $D_{3}$ are dimensionless constants defined by the relationships $\left\langle h^{n}\right\rangle=D_{n}\langle h\rangle^{n}$. The use of Equations 3 and 4 was examined previously (Holt et al., 2006), in which it was shown that low extracellular $\mathrm{Ca}^{2+}$ and the postsynaptic blocker 6-cyano-7nitroquinoxaline-2,3-dione (CNQX) had the expected results, leading to exponents of 1 and 1.5 , respectively.

Monte Carlo simulations were used to check the effects of nonstationarity on shot-noise ensemble estimates. In the simulations, the timing of quantal events was assumed to obey Poisson statistics, whereas qsize was taken from gamma distributions with a coefficient of variation of 0.4 (for details, see Holt et al., 2006). The events were represented by impulses with amplitudes proportional to qsize. Impulses were convolved with an mEPSP, $f(t)=\alpha t \cdot \exp (-\alpha t)$, normalized to unity amplitude. On each trial, qrate, qsize, or both parameters were varied as a function of elapsed time. Several trials were run and were summarized by ensemble means, variances, and skews. Simulations confirmed that Equations 3 and 4 could be applied to nonstationary data (see Fig. 2).

Data acquisition and computer processing. Data acquisition and delivery of efferent shocks were controlled by custom-made Spike2 scripts executed on a Pentium 4 computer with a microl401 interface (Cam- 
bridge Electronic Design, Cambridge, UK). The microelectrode signal was low-pass filtered at 1 $\mathrm{kHz}$ (four-pole Bessel; model 432; Wavetek, San Diego, CA). Spectral analyses showed that the quantal power of the unfiltered signal was attenuated at $1 \mathrm{kHz}>1000 \times$ from its lowfrequency asymptote. Records were sampled at $10 \mathrm{kHz}$ by a 12-bit analog-to-digital converter. Efferent shock times were controlled from a digital-output port.

After each experiment, Spike2 data files were exported to Macintosh computers (Apple Computers, Cupertino, CA) and processed using custom programs written in IgorPro 5.0 (WaveMetrics, Lake Oswego, OR).

Physiological testing. In both extracellular and intracellular recordings, background activity, $2-5 \mathrm{~s}$ in duration, was recorded before our standard efferent stimulus, a train of 20 shocks with adjacent shocks separated by $5 \mathrm{~ms}$, was delivered to the cross-bridge. Several trains were presented and shock amplitude was adjusted to result in a clear response in the absence of antidromic activation. Current intensities ranged from 40 to $300 \mu \mathrm{A}$. To study the effects of efferent stimulation on synaptic activity, it was necessary to block spikes in the afferent. Tetrodotoxin could not be used because it also blocked conduction in efferent axons. Instead, QX-314 [2-(triethylamino)- $N$-(2,6-dimethylphenyl)acetamide] (40 mM), a charged lidocaine derivative, was added to the micropipette solution and blocked spikes in the recorded afferent, typically within 30-60 s of impalement.

Intracellular recordings were analyzed only if the membrane potential was more negative than $-40 \mathrm{mV}$. Typically, it was near $-60 \mathrm{mV}$. To characterize the efferent response to our standard (20-shock) train, we averaged 10-25 individual trials, which were separated by $3-5 \mathrm{~s}$ to allow each response to return to baseline. Average responses to single shocks were typically based on 150-250 trials repeated every 500 $\mathrm{ms}$. Pharmacological agents usually took $30 \mathrm{~s}$ to $2 \mathrm{~min}$ to begin acting and another $2-5 \mathrm{~min}$ to reach maximal effect. Washout times were quite variable and could be longer than $10 \mathrm{~min}$. For that reason, we used extracellular spike recordings with their longer holding times to test for drug reversibility. In all recordings, efferent shock artifacts were canceled off-line by first computing an average artifact and then subtracting it from the records.

Solutions. $\quad \alpha$-Bungarotoxin $(\alpha$-BTX), dihydro- $\beta$-erythroidine (DH $\beta$ E), ICS-205,390 (3-tropanylindole-3-carboxylate methiodide; tropisetron) (ICS), methyllycaconitine (MLA), QX-314, and strychnine (STR) were obtained from Sigma (St. Louis, MO); D-2-amino-5phosphonovalerate (AP-5) and CNQX were from Tocris Cookson (Ellisville, MO); apamin was from Alomone Labs (Jerusalem, Israel); and scyllatoxin (ScTX) was from Peptides International (Louisville, KY). QX314 was dissolved in $3 \mathrm{M} \mathrm{KCl}$. All other drugs were prepared as concentrated stock solutions, which were then added to the control solution to achieve the desired concentrations before each experiment.

Electron microscopy. Turtles were decapitated, the skull was bisected, and the temporal bones were fixed by an intra-labyrinthine perfusion with a trialdehyde fixative (Lysakowski and Goldberg, 1997) dissolved in a turtle Ringer's solution. Temporal bones were postfixed in the same trialdehyde fixative until dissection. Posterior cristae were dissected individually, dehydrated in a graded series of ethanols, and embedded in Araldite (Fluka, Ronkonkoma, NY). Ultrathin sections were cut on a

$J$
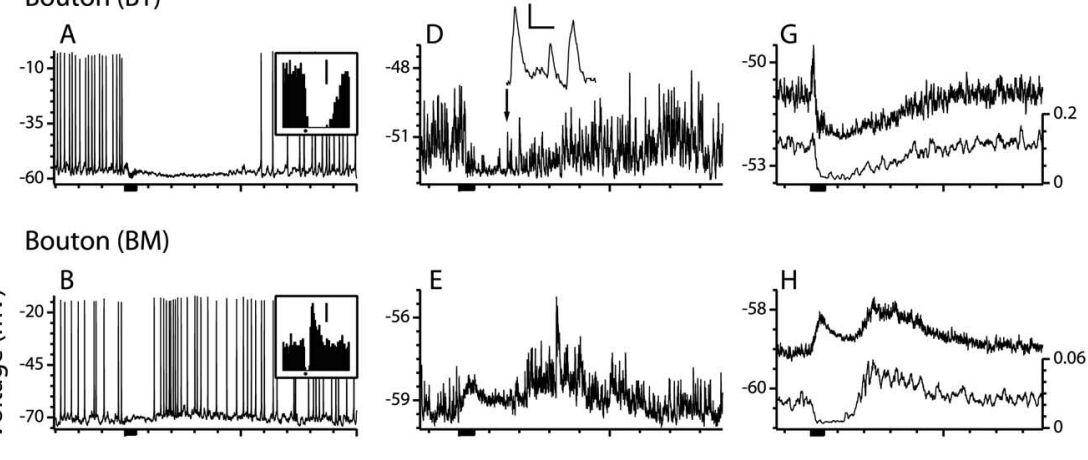

文
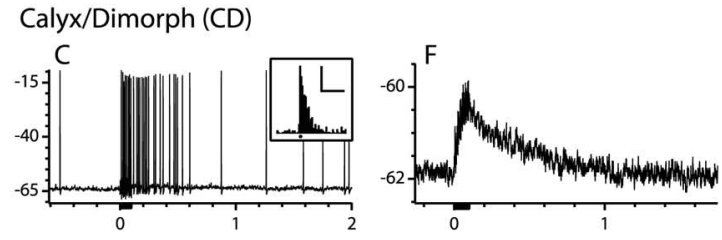

Time (s)

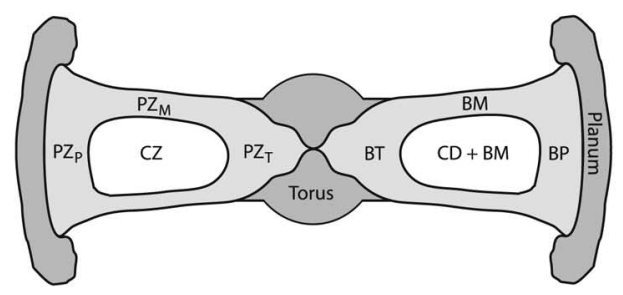

Figure 1. Responses to efferent stimulation. Intracellular recordings were obtained from bouton (BT and BM) and calyx( inset (1 s) also applies to the insets for $\boldsymbol{A}$ and $\boldsymbol{B}$; vertical calibration bars: 10 ( $\boldsymbol{A}$ and $\boldsymbol{B}$ insets) and 30 ( $\boldsymbol{C}$ inset) spikes/s. $\boldsymbol{D}-\boldsymbol{F}$ . and left axis in millivolts) and variances (bottom traces and right axis), same units as in $\boldsymbol{D}-\boldsymbol{F}$. The number of trials is as follows: $\boldsymbol{G}$ hemicristae. Each hemicrista extends from the planum semilunatum (Planum) to the nonsensory torus (Torus) and includes a CZ and PZ. The $\mathrm{PZ}$ is divided into a $\mathrm{PZ} Z_{T}$ near the torus, $\mathrm{aPZ}$ near the planum, and a $\mathrm{PZ} Z_{M}$ between the other two regions. Type I hair cells (D) and bouton (BM) afferents; the PZ is innervated by bouton afferents, further distinguished into those near the torus (BT), in intermediate regions (BM), or near the planum (BP). $\boldsymbol{K}$, Presynaptic (PRE) efferent innervation of type Il hair cells and postsynaptic (POST) innervation of bouton and calyx fibers are illustrated.

diamond knife (Delaware Diamond Knives, Wilmington, DE), collected on Formvar-coated single slot grids, and stained with uranyl acetate and lead citrate (Lysakowski and Goldberg, 1997).

Three posterior cristae, each taken from a different animal, were examined. Two of the three specimens were cut longitudinally through the entire length of the crista, including the peripheral zones near the nonsensory torus $\left(\mathrm{PZ}_{\mathrm{T}}\right)$, the central zones $(\mathrm{CZ})$, and the peripheral zones near the planum semilunatum of both hemicristae $(\mathrm{PZ}$ ) (see Fig. $1 \mathrm{~J}$ ). Six serial sections were examined in one case and 16 serial sections in the other case. The third specimen was sectioned transversely to examine the intermediate part of the peripheral zone $\left(\mathrm{PZ}_{\mathrm{M}}\right)$ on one slope of a hemicrista; the sample consisted of 36 serial sections. In all samples, every highly vesiculated efferent bouton was inspected. Summing over all three samples, there were 105 efferent boutons, many of which were not completely contained within the sample boundaries, which may help to explain why only 54 efferent synapses were identified.

Statistical procedures. Unless otherwise stated, values are expressed as means \pm SEM. Unpaired $t$ tests were used to determine whether means 
differed from zero or other values. Drug effects were evaluated by paired $t$ tests.

\section{Results}

Four classes of afferents have different efferent responses

There are four populations of afferents having distinctive locations in each hemicrista (Brichta and Peterson, 1994; Brichta and Goldberg, 2000a) (Fig. 1 J). Calyx-bearing (CD) afferents, including calyx and dimorphic fibers, are confined to the central zone. Calyx fibers innervate type I hair cells, whereas dimorphic fibers provide a mixed innervation to type I and type II hair cells. The two calyx-bearing groups are considered together because they cannot be distinguished physiologically (Brichta and Goldberg, 2000a,b). Bouton (B) afferents can be separated into BT units in the peripheral zone near the nonsensory torus, $\mathrm{BP}$ afferents in the peripheral zone near the planum semilunatum, and BM afferents in the peripheral and central zones at intermediate locations (Fig. $1 J)$. We studied the efferent responses of BT, BM, and CD units. $\mathrm{BP}$ units were not investigated because their thin axons and small, excitatory efferent responses made them difficult to impale and characterize. Of a total sample of 355 units (118 CD, 104 BT, 133 $\mathrm{BM}$ ), spike responses were examined in 108 units (31 CD, $32 \mathrm{BT}$, $45 \mathrm{BM})$ and underlying synaptic events, uncontaminated by spikes, in 247 units ( $87 \mathrm{CD}, 72 \mathrm{BT}, 88 \mathrm{BM}$ ).

In the following, it was important to distinguish efferent actions on hair cells from those on afferent processes. Taking the afferent synapse as a reference point, the former were termed presynaptic and the latter as postsynaptic (Fig. $1 \mathrm{~K}$ ).

Spike responses obtained after impalement were similar to those observed previously in extracellular recordings (Brichta and Goldberg, 2000b). Figure $1 A-C$ depicts the spike responses to trains of 20 efferent shocks. BT afferents show a long-lasting inhibition (Fig. $1 A$ ). The discharge rate slowly returns to baseline values with no evidence of a postinhibitory excitation (Fig. $1 \mathrm{~A}$, inset). BM units are also inhibited by efferent stimulation, but the inhibition is shorter in duration than in BT units and is followed by an excitatory rebound (Fig. $1 B$ ). CD afferents respond with a prolonged excitatory response (Fig. 1C).

The synaptic events underlying these responses are illustrated with records from another set of units whose spikes were blocked by QX-314 (Fig. 1D-F). As was shown previously (Holt et al., 2006), the high-frequency events seen after spike elimination have several properties expected of miniature EPSPs (mEPSPs), so-called synaptic quanta arising from hair cells: their rate is reduced when external $\mathrm{Ca}^{2+}$ is lowered; their size is diminished by the postsynaptic blocker CNQX; they occur at high rates $(\approx 500 / \mathrm{s})$ in the absence of vestibular stimulation; their shapes and mean sizes vary only slightly as their rate changes; and their timing obeys Poisson statistics. Furthermore, their shapes are typical of mEPSPs (Fig. $1 D$, inset). In BT units (Fig. $1 D$ ), efferent stimulation results in an almost complete inhibition of synaptic traffic, followed by a gradual recovery. The decline in synaptic activity is associated in this particular case with a hyperpolarization of slightly over $1 \mathrm{mV}$. In BM units (Fig. $1 E$ ), inhibition is succeeded by a burst of synaptic activity. In the illustrated unit, there is also a depolarization during the inhibition. Because a reduction in quantal activity should lead to a postsynaptic hyperpolarization, the depolarization, which was seen in several BT/BM units, must arise from some source other than hair-cell mEPSPs. Later, we will provide evidence that a postsynaptic efferent action is responsible for the depolarization. Finally, in the CD unit (Fig. $1 F$ ), there is an efferent EPSP of long duration without an associated change in quantal traffic.

\section{BM Afferent}
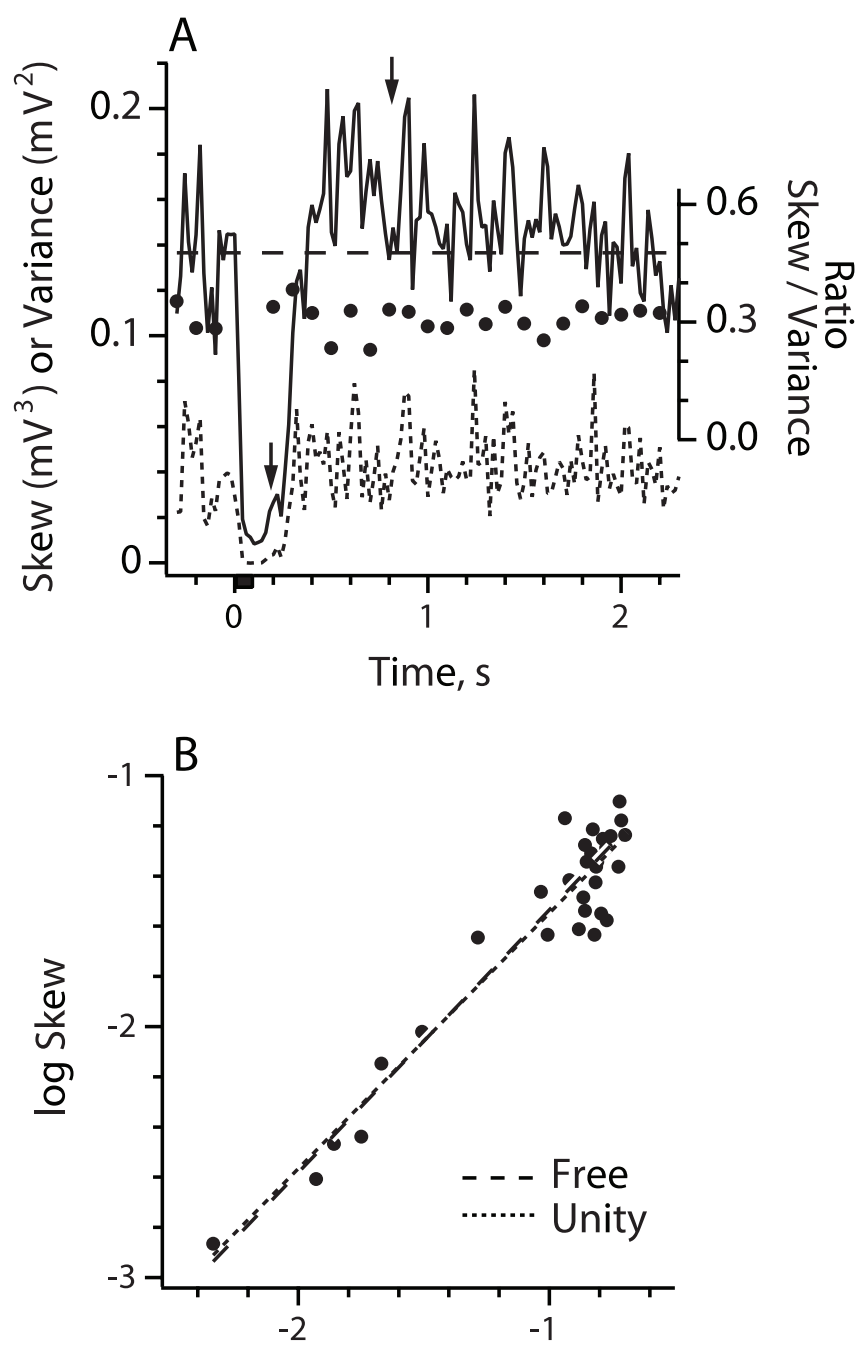

log Variance

Figure 2. Quantal analysis of efferent responses distinguishes between actions targeted to hair cells and afferents. After spikes were blocked with QX-314, intracellular recordings were obtained from a BM afferent during repeated efferent shock trains (20 shocks at 200/s). $\boldsymbol{A}$, Ensemble variance (solid line, top) and skew (dotted line, bottom), based on 20 trials, were calculated in $20 \mathrm{~ms}$ bins. Variance was corrected by subtracting a residual value, the variance when the skew was extrapolated to zero. Horizontal dashed line is the average prestimulus variance. The ratio of skew to variance (filled circles), which can be used as a relative measure of quantal size, was calculated in $100 \mathrm{~ms}$ bins starting $200 \mathrm{~ms}$ into the response, as well as before the response. $\boldsymbol{B}$, When the skew is plotted against the corrected variance in double-logarithmic coordinates, a log-log regression (dashed line) has a slope near unity (dotted line), consistent with changes in quantal rate rather than quantal size. Points for regression were taken from $A$ between the two arrows.

\section{Ensemble variances distinguish between actions targeted to} hair cells and afferents

The responses after spikes are blocked can be characterized by calculating ensemble means and variances (Fig. $1 G-I$ ). Changes in the ensemble variance, which are seen in the BT (Fig. 1G) and BM (Fig. $1 H$ ) units, but not in the CD unit (Fig. $1 I$ ), reflect variations in quantal transmission. It might be expected that an efferent action on hair cells would result in a modulation of qrate rather than qsize. To distinguish between these two possibilities, we plotted the ensemble skew $\left(\lambda_{3}\right)$ versus the ensemble variance $\left(\lambda_{2}\right)$. As developed in Materials and Methods, for a variation in 
qrate $\lambda_{3}$ should be linearly related to $\lambda_{2}$ (Eq. 3), whereas $\lambda_{3}$ should be proportional to $\lambda_{2}^{1.5}$ for a qsize variation (Eq. 4). The skew and variance are shown for the efferent response of an individual BM unit (Fig. $2 A)$. In the plot, we included points from efferent inhibition and postinhibitory excitation but not from rest (Fig. $2 \mathrm{~A}$, arrows). A log-log regression gives a slope of $1.02 \pm 0.06$, consistent with a qrate variation (Fig. $2 B$ ). Figure $2 A$ also includes the ratio, $\lambda_{3} / \lambda_{2}$, which should be proportional to qsize. As expected, the ratio is nearly constant during transitions from inhibition to rebound excitation and then to rest. Multiplying the moments ratio by 2.3, a typical value of the quantity $\left(D_{2} I_{2} / D_{3} I_{3}\right)$ in Equation 3 (Holt et al., 2006), gives an average mEPSP size, $\langle h\rangle=0.71 \mathrm{mV}$. Nearlinear relationships between $\lambda_{3}$ and $\lambda_{2}$ were obtained in $11 \mathrm{BT} / \mathrm{BM}$ units (4 BT and $7 \mathrm{BM}$ ); the mean \pm SE log-log slope was $1.03 \pm 0.02$.

The skew-variance relationship is consistent with the conclusion that changes in ensemble variance are the result of variations in quantal rate rather than quantal size. As such, variance changes can be taken as reflecting efferent actions on hair cells. In this regard, reliance on postsynaptic voltages is ambiguous because a presynaptic inhibition can be associated with a depolarization presumably arising postsynaptically (Fig. 1E). Based on their efferent innervation patterns, we would predict that some of the responses of the $\mathrm{BT} / \mathrm{BM}$ units arise presynaptically, whereas most of the responses in the CD unit arise postsynaptically. The presence of variance changes in $\mathrm{BT} / \mathrm{BM}$ units (Fig. $1 G, H$ ), but not in CD units (Fig. $1 I$ ), is consistent with the conclusion.

\section{Single efferent shocks evoke detectable efferent responses}

Although 20-shock efferent trains were useful in classifying units, shock artifacts could obscure early portions of the response. Fortunately, detectable responses were evoked in most units by single shocks. Figure 3 includes single-shock responses for three individual units, each one belonging to a different afferent class. In the BT afferent (Fig. 3A), an initial depolarization lasting slightly under $10 \mathrm{~ms}$ is followed by a hyperpolarization of comparable magnitude continuing for $400 \mathrm{~ms}$. A brief increase in variance gives way to a more prolonged decrease (Fig. $3 B$ ). The sequential changes in variance are consistent with the quantal rate first rising above and then falling below prestimulus values.

A similar sequence of events is seen in the BM unit (Fig. 3C,D) although the prolonged hyperpolarization and variance decrease are shorter in duration than those seen in the BT unit (Fig. $3 A, B$ ). There is a postinhibitory rebound in BM units with single efferent shocks, but it is typically much smaller than that seen after 20 shock trains. In addition, the decrease in the variance evoked by single shocks in both BT and BM units is invariably associated with a hyperpolarization rather than the depolarization often seen in the 20-shock response (Fig. $1 E$ ).

In contrast to the inhibition seen in the BT/BM units, the single-shock response of the CD unit consists of a depolarization that is not associated with a variance change (Fig. $3 E, F)$, similar to observations made with 20 shocks (Fig. 1I).

Table 1 summarizes the single-shock responses for the three unit classes. Latent periods are shortest in CD units and longest in BT units. The amplitudes of the early depolarization or subsequent hyperpolarization are similar in BT and BM units. The durations of the initial depolarizations are also comparable for the two bouton groups, whereas the hyperpolarization is shorter in BM units. A long depolarization is characteristic of CD units.

\section{CNQX confirms the identification of efferent responses on hair cells and afferents}

Ensemble variances (Fig. $3 B, D$ ) indicate that the single-shock responses in $\mathrm{BT} / \mathrm{BM}$ afferents are primarily attributable to the activation of efferent synapses on hair cells rather than on afferent processes. The almost flat variance curve of Figure $3 F$ suggests a postsynaptic origin for the efferent responses in CD units. Furthermore, latent periods are longer in $\mathrm{BT} / \mathrm{BM}$ units than in $\mathrm{CD}$ 
units by $1.0-1.6 \mathrm{~ms}$ (Table 1 ), which is approximately the value of a single synaptic delay in turtles (Yamashita, 1986). The excitation seen in CD units is presumably attributable to the monosynaptic connections that efferents make with calyx fibers. The longer latency for BT/BM units can be explained by the need for transmission across an additional synapse for a hair-cell action to affect the afferent.

To verify these interpretations, we used the glutamate receptor antagonists CNQX and AP-5, which block afferent synaptic transmission in this preparation and, hence, can be used to isolate afferents from their hair cells (Holt et al., 2006). Because the addition of AP-5 did not appear to change the results, in many cases we only used CNQX. For BT/BM units, CNQX blocks both the initial depolarization and the subsequent hyperpolarization evoked by single shocks (Fig. 4A), consistent with a presynaptic origin for both components. In addition, the variance changes evoked by either single (number of units, $n=4$ ) or multiple ( $n=$ 15) shocks (Fig. 4B) are almost completely eliminated.

A postsynaptic component in BT/BM units, although seldom present in single-shock responses, was frequently produced by 20 -shock trains. This can be seen in the BM unit of Figure $4 B$, in which the initial part of the control record consisted of a depolarization associated with a variance decrease. When synaptic transmission from the hair cell was blocked by CNQX, the depolarization persisted, although the ensemble variance became flat. The early part of the response is similar in the two records. This can be explained by fact that efferent stimulation and CNQX both abolish quantal activity. When efferent stimulation is less effective, CNQX can shift the response in a depolarizing direction by unmasking postsynaptic depolarization from presynaptic inhibition.

CNQX almost completely abolished the postinhibitory rebound in BM units (Fig. $4 B$ ), reflected as either a depolarization or a transient variance increase $(n=7)$. Its elimination implies that the rebound, like the preceding inhibition, is a presynaptic effect.

The presence of calyx endings effectively precludes efferents from reaching type I hair cells. A postsynaptic origin for the efferent depolarization is consistent with its short latent period and the absence of an associated variance change, to which we can add the observation, made in three CD units, that the response is virtually unaffected by CNQX (Fig. 4C).

\section{Pharmacology identifies neurotransmitter receptors and intracellular signaling mechanisms}

We used pharmacological agents in an attempt to identify the neurotransmitter receptors and the subsequent intracellular signaling mechanisms involved in efferent actions. For BT/BM units, we first consider presynaptic (hair-cell) mechanisms. Next, the postsynaptic receptors involved in the efferent excitation of $\mathrm{CD}$ units are considered. Finally, we compare the pharmacology of postsynaptic (afferent) responses in BT/BM and CD units. Table 2 summarizes the number of units studied, the concentrations used, and the average effects ( \pm SEM) for ICS, an $\alpha 9 / \alpha 10$ blocker; SK blockers (apamin and scyllatoxin); and the nicotinic antagonist $\mathrm{DH} \beta \mathrm{E}$. Only 20 -shock responses are summarized. For BT/BM units, to avoid contamination with postsynaptic responses, we calculated the ratios of ensemble variances for efferent responses and background. Synaptic responses for CD units were measured as changes in membrane voltage because there were no associated variance changes. This was also done for BT/BM units; except for the confounding effects of
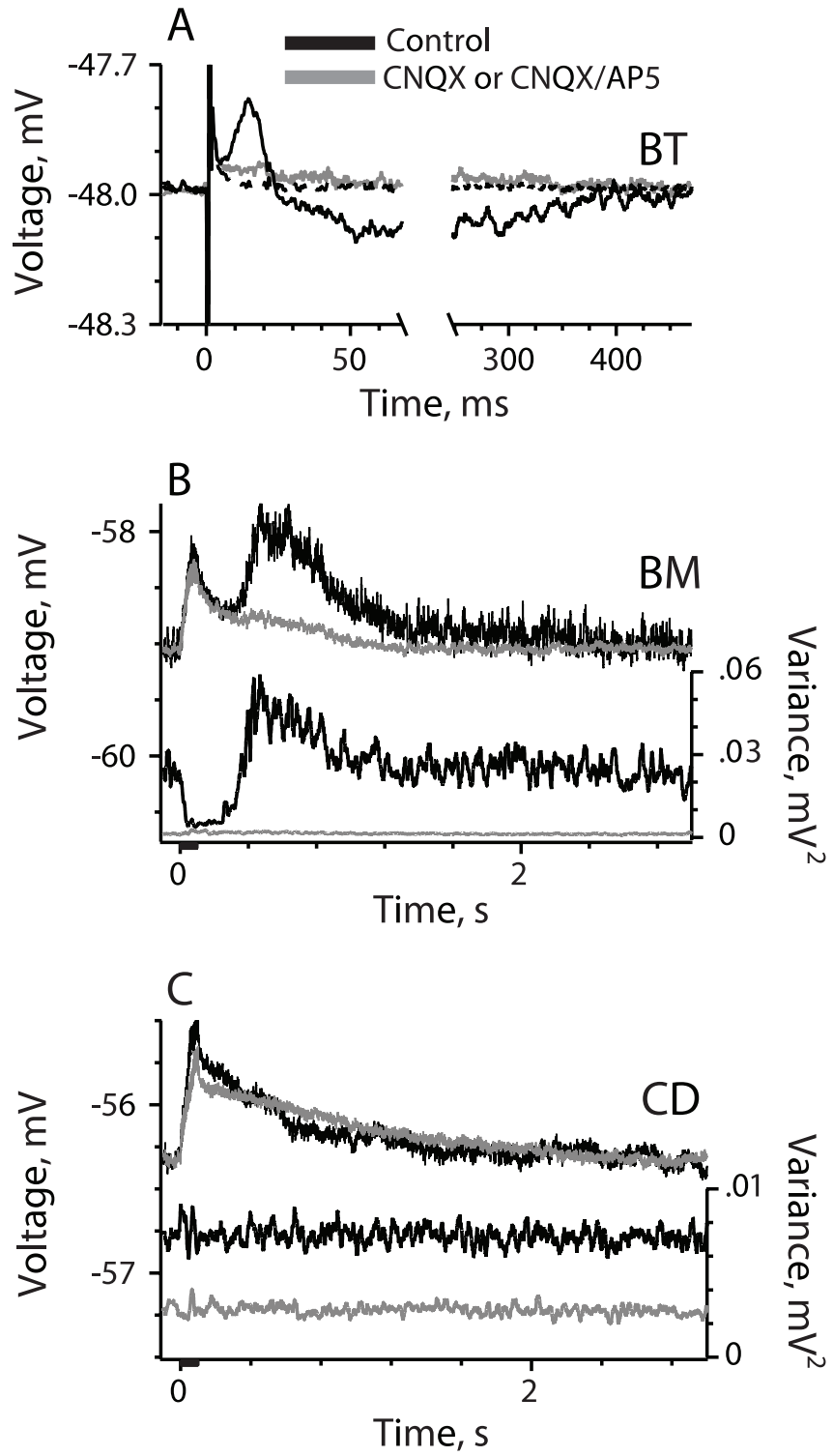

Figure 4. CNQX distinguishes between presynaptic actions on hair cells and postsynaptic actions on afferent fibers. Responses are compared before and during $50 \mu \mathrm{M}$ CNQX, which blocks synaptic transmission from hair cells as indicated, when shown, by the flat variance curves. $\boldsymbol{A}$, In a BT afferent, CNQX eliminates both the early depolarization and the subsequent hyperpolarization in the response to single efferent shocks. The dashed trace is the ensemble mean of extracellular records after the impalement, displaced so that its prestimulus value coincides with the prestimulus value of the intracellular mean. $\boldsymbol{B}$, Ensemble mean (top) and variance (bottom) responses in a BM afferent to the standard efferent train (20 shocks at 200/s). The depolarization during CNQX is postsynaptic in origin. C, Ensemble means (top) and variances (bottom) in a CD afferent (20 shocks at 200/s). CNQX does not affect efferent-mediated depolarization. In all cases, spikes were blocked with QX-314, and quantal transmission was blocked with $50 \mu \mathrm{m}$ CNQX. In C, $100 \mu \mathrm{m}$ AP-5 was superfused with CNQX. In this and subsequent figures, unless otherwise stated, spikes were blocked by intracellular QX-314. Efferent stimulus consisted of either single shocks or multiple shocks ( 20 shocks at 200/s). Ensemble means and variances were based on $150-250$ repetitions ( 1 shock) or $10-25$ repetitions ( 20 shocks).

postsynaptic responses, voltage and variance changes led to similar conclusions.

Presynaptic components in BT/BM afferents

An obvious receptor candidate for the efferent-mediated inhibition in $\mathrm{BT} / \mathrm{BM}$ afferents is the $\alpha 9 / \alpha 10$ nicotinic receptor on hair cells (Elgoyhen et al., 2001; Gomez-Casati et al., 2005). Figure 5A 
Table 2. Effects of drugs on 20-shock efferent responses, turtle posterior crista

\begin{tabular}{|c|c|c|c|c|c|c|c|c|c|c|}
\hline \multirow[b]{2}{*}{ Drug } & \multirow[b]{2}{*}{ Conc $(\mu \mathrm{m})$} & \multirow[b]{2}{*}{ Measure } & \multicolumn{4}{|l|}{$C D$} & \multicolumn{4}{|c|}{$\mathrm{BT} / \mathrm{BM}$} \\
\hline & & & $n$ & Control & Drug & $\%$ Block & $n$ & Control & Drug & $\%$ Block \\
\hline ICS & 10 & $\begin{array}{l}\text { Voltage } \\
\text { Variance }\end{array}$ & 8 & $1.09 \pm 0.20^{* *}$ & $0.70 \pm 0.14^{* *}$ & $35^{* *}$ & 8 & $\begin{array}{l}-0.58 \pm 0.17^{*} \\
-0.50 \pm 0.05^{* *}\end{array}$ & $\begin{array}{l}0.24 \pm 0.06^{* *} \\
0.02 \pm 0.04\end{array}$ & $\begin{array}{l}141^{* *} \\
108^{* *}\end{array}$ \\
\hline $\begin{array}{l}\text { SK blockers } \\
\text { Apamin } \\
\text { Scyllatoxin }\end{array}$ & $\begin{array}{l}0.3-1 \\
0.2-1\end{array}$ & $\begin{array}{l}\text { Voltage } \\
\text { Variance }\end{array}$ & 0 & & & & 11 & $\begin{array}{l}-0.21 \pm 0.13 \\
-0.38 \pm 0.11^{*}\end{array}$ & $\begin{array}{l}4.0 \pm 0.9^{* *} \\
1.7 \pm 0.5^{* *}\end{array}$ & $\begin{array}{r}2000^{* *} \\
550^{* *}\end{array}$ \\
\hline $\mathrm{DH} \beta \mathrm{E}$ & 0.3 & $\begin{array}{l}\text { Voltage } \\
\text { Variance }\end{array}$ & 19 & $0.68 \pm 0.09^{* *}$ & $0.20 \pm 0.04^{* *}$ & $70^{* *}$ & 11 & $\begin{array}{c}0.00 \pm 0.03 \\
-0.44 \pm 0.07^{* *}\end{array}$ & $\begin{array}{l}-0.36 \pm 0.14^{*} \\
-0.43 \pm 0.07^{* *}\end{array}$ & $\begin{array}{c}3500^{* *} \\
1\end{array}$ \\
\hline
\end{tabular}

Effects on average responses, 20 -100 ms after the start of the 20-shock efferent train. Conc, Drug concentrations; Voltage (in mV), average voltage during shock train minus background voltage; Variance, 1 - var(eff)/var(back), where $\operatorname{var}($ back) and var(eff) are average ensemble variances before and during the train, respectively; $n$, number of units. Mean \pm SEM in the absence (Control) and presence (Drug) of drug; statistical tests for individual means, unpaired $t$ test. $\%$ block, $100 *(1-$ Drug/Control); $0-100 \%$, drug response smaller but of same sign as control; $>100 \%$, drug response of opposite sign from control response; statistical tests for \% block, paired $t$ test between Drug and Control. For all statistical tests, ${ }^{*} p<0.05 ;{ }^{* *} p<0.01$.

shows that ICS abolished the single-shock response of a BT unit, consistent with the conclusion that both the initial depolarization and the following inhibition result from the activation of $\alpha 9 / \alpha 10$. Similar single-shock results were obtained in seven other BT/BM units. ICS had a similar effect on the response to 20 shocks, eliminating changes in both the voltage and variance (Fig. $5 B, C$ ). Table 2 summarizes the effects of ICS on the efferent inhibition in response to multiple shocks. Effects, measured as variance changes, were completely abolished as indicated by highly significant negative control responses being replaced by nonsignificant, near-zero drug responses (Table 2). The existence of a postsynaptic depolarization is verified in the table by the presence of a depolarizing voltage response in the face of a negligible variance response. This is the first suggestion of a postsynaptic efferent component that is pharmacologically distinct from the $\alpha 9$ / $\alpha 10$-mediated presynaptic inhibition.

Because of the unusual pharmacology of $\alpha 9 / \alpha 10$ receptors, they cannot be uniquely identified by any single antagonist. ICS, for example, blocks both $\alpha 9 / \alpha 10$ and 5- $\mathrm{HT}_{3}$ receptors (Rothlin et al., 2003). For that reason, we used several blockers whose effectiveness would be consistent with the presence of $\alpha 9 / \alpha 10$. Both intracellular synaptic and extracellular spike recordings were used. Concentrations and the number of units tested are as follows: ICS $(0.3-10 \mu \mathrm{M} ; n=16,25)$, STR $(1-10 \mu \mathrm{M} ; n=0,5)$, MLA $(0.1-1 \mu \mathrm{M} ; n=6,9)$, and $\alpha$-BTX $(1 \mu \mathrm{M} ; n=0,2)$. The two entries for the number of units refer, respectively, to synaptic and spike recordings. All of these compounds blocked inhibitory efferent responses by $90-100 \%$.

Because drug washout could take considerable time, we exploited the longer holding times of extracellular spike recordings to test for reversibility. In the unit shown in Figure $5 D$, for example, the blocking of efferent inhibition by ICS was reversed after 8 min. The effects of ICS were reversed on 16 occasions, STR once, MLA three times, and $\alpha$-BTX once.

Based on work in other hair-cell systems (Nenov et al., 1996; Yuhas and Fuchs, 1999; Oliver et al., 2000), the initial depolarization could represent an excitatory action resulting from the activation of $\alpha 9 / \alpha 10$ nAChRs, whereas the following hyperpolarization could reflect the subsequent activation of SK channels by $\mathrm{Ca}^{2+}$ entry through $\alpha 9 / \alpha 10$. To examine this scenario, we treated preparations with the SK blockers apamin or ScTX. Both blockers had similar effects and will be considered together. Figure $6 \mathrm{~A}$ shows the effect of ScTX on the average voltage response of a BT unit to single efferent shocks. The small, biphasic control response, consisting of a depolarization followed by a more prolonged hyperpolarization, is replaced by a much larger, prolonged depolarization correlated with a monophasic increase in variance (Fig. $6 B$ ). Similar results were obtained with SK blockers in four other BT/BM units responding to single shocks and in 11 units during 20-shock stimulation (Table 2). That the activation of presynaptic $\alpha 9 / \alpha 10$ after SK block is responsible for the purely depolarizing responses is indicated by their being almost completely blocked by ICS (Fig. 6D) $(n=7)$ and by CNQX $(n=6$; data not shown).

The effects of either apamin or ScTX were difficult to reverse, possibly because of their high binding affinities (Stocker et al., 2004). At the same time, there can be little question as to the specific action of these agents because they produced unique, positive effects. The effects were unique in that the monophasic excitation was associated with a variance increase and was blocked by CNQX, which distinguished it from the postsynaptic excitation seen in CD and BT/BM units.

The depolarizing response remaining after ScTX block can be taken as the isolated nicotinic (nAChR) excitatory response. By subtracting the excitatory response from the original control response $(\mathrm{nAChR}+\mathrm{SK})$, we get an inferred SK response. These manipulations are illustrated in Figure $6 C$. The nAChR and inferred SK responses are of comparable magnitude $(\sim 2 \mathrm{mV})$ and much larger than either the peak depolarization or the subsequent peak hyperpolarization of the control response, both $\sim 0.2$ $\mathrm{mV}$ in size. On average, the single-shock response obtained with SK blockers was several times larger than control responses (peak voltage, $1.43 \pm 0.36$ vs $0.33 \pm 0.09 \mathrm{mV} ; n=5 ; p<0.05$ ). From this, we might conclude that the relatively small sizes of the control depolarization and hyperpolarization are the result of a nearbalance between the nAChR and SK components. In addition, the decomposition allowed us to measure the delay between the two components. In Figure $6 C$, the delay was $0.4 \mathrm{~ms}$. Two other examples gave delays of 0.4 and $1.4 \mathrm{~ms}$.

For the decomposition to be valid, the interaction between the two components has to be close to linear. An alternative explanation is that there is saturation in the control inhibition. Two sources of saturation are a silencing of quantal transmission or the activation of all available SK channels. Both mechanisms seem unlikely. Evidence against quantal saturation is the variance not approaching zero during peak inhibition, although instrumental (residual) variance has already been subtracted (Fig. $6 B$ ). On average, the one-shock decrease in variance, measured in 32 units, amounted to only $21 \pm 1.5 \%$ of the background variance. SK saturation would seem precluded by the observation that the inhibition, measured as a decrease in ensemble variance in the same 32 units, became substantially larger when single shocks were replaced by 20 -shock trains in the absence of drugs (one shock, $-0.0078 \pm 0.0001 \mathrm{mV}^{2}$ vs 20 shocks, $-0.0363 \pm 0.0062$ $\mathrm{mV}^{2}$ ). Expressed as a ratio, the 20-shock variance response was $4.6 \pm 0.51$ times larger. 

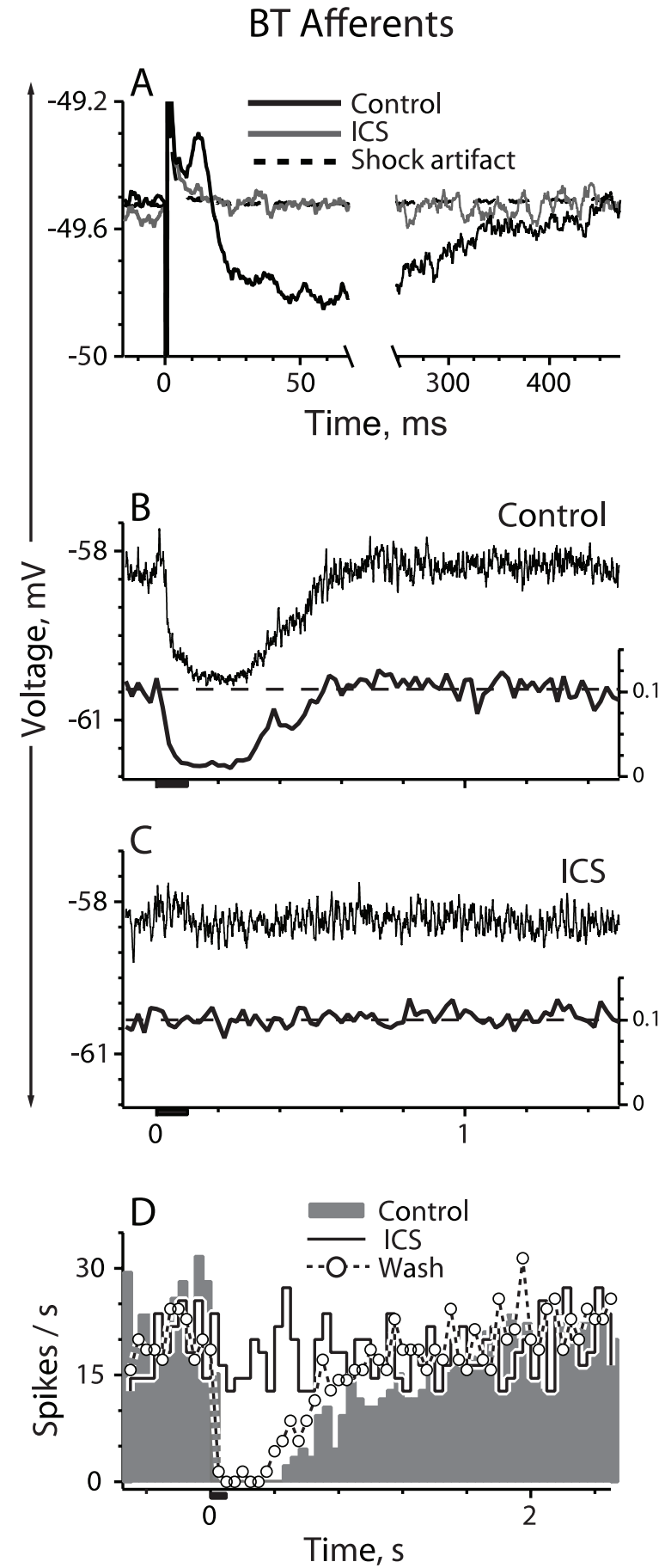

Figure 5. ICS, a blocker of $\alpha 9 / \alpha 10$ nicotinic receptors, abolishes efferent responses of BT afferents. Responses are compared before and during application of $10 \mu \mathrm{M}$ ICS. A, ICS completely blocks both the early depolarization and the subsequent hyperpolarization seen in the average voltage response to single efferent shocks. Shock artifact obtained from extracellular record displaced so that its prestimulus value coincides with the prestimulus value of the intracellular mean. $\boldsymbol{B}, \boldsymbol{C}$, Ensemble means (top trace) and variances (bottom trace) in another BT afferent; control responses to multiple shocks ( $\boldsymbol{B})$ are abolished by ICS ( $\boldsymbol{C}$. Dashed line in $\boldsymbol{B}$ and $\boldsymbol{C}$ is the average prestimulus variance. For other details, see legend to Figure 4. $\boldsymbol{D}$, To demonstrate reversibility, average response histograms from the spike discharge in an extracellularly recorded BT afferent were obtained before, during, and after the application of $10 \mu \mathrm{m} \mathrm{ICS}$.

Synaptic mechanisms distinguishing BT and BM units In most respects, the early excitation and the subsequent inhibition in BT and BM units have similar electrophysiological and pharmacological properties. In one respect, however, the two
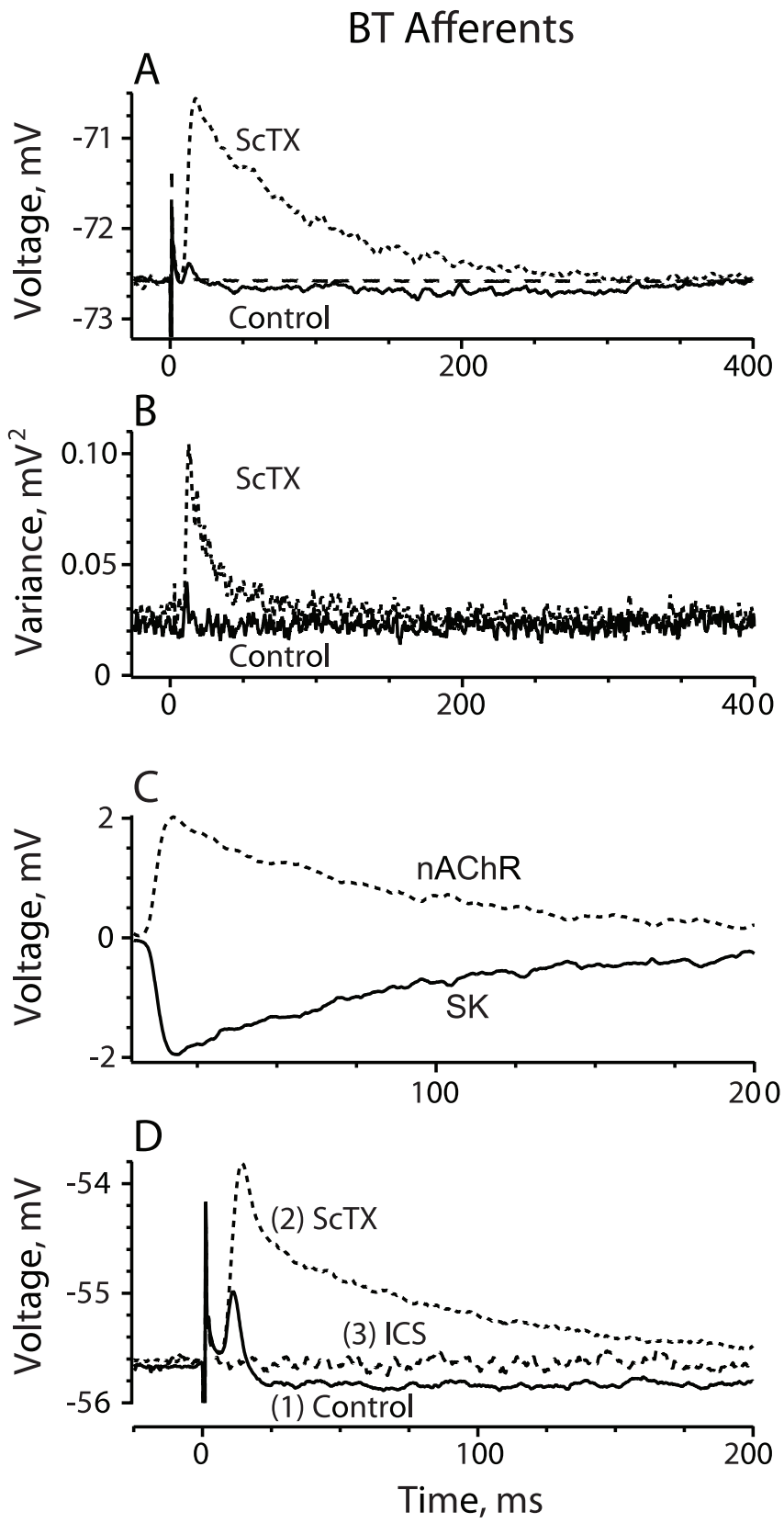

Figure 6. ScTX, an SK blocker, converts efferent responses from a biphasic excitation-inhibition to a monophasic excitation. $\boldsymbol{A}, \boldsymbol{B}$, Ensemble means $(\boldsymbol{A})$ and variances $(\boldsymbol{B})$, in response to single shocks. The dashed trace in $\boldsymbol{A}$ is the ensemble mean of extracellular records after the impalement, displaced so that its prestimulus value coincides with the prestimulus value of the intracellular mean. ScTX $(0.4 \mu \mathrm{m})$ converted the small biphasic voltage response into a large, prolonged monophasic depolarization $(\boldsymbol{A})$ associated with a substantial increase in the variance (B). C, The response after SK block is taken as the nicotinic response (nAChR); subtracting the control response from the $S c T X$ response in $\boldsymbol{A}$ is identified as the SK response. $\boldsymbol{D}$, The biphasic average voltage response $(1$, Control) in a BT unit is converted to an exclusively depolarizing response by $1 \mu \mathrm{m} S \mathrm{TX}$ (2), which is then completely blocked by $10 \mu \mathrm{m}$ ICS (3). For other details, see legend to Figure 4.

unit groups differ quantitatively. With either single (Fig. 3, compare $A, C$; Table 1) or multiple (Fig. 1, compare $G, H$ ) shocks, BM units can be distinguished from BT units by their shorter inhibitory periods. Observations with SK blockers provided a possible basis for the difference. In particular, the depolarization remaining after SK block is smaller and briefer in BM compared with BT units (Fig. 7C). Using 20-shock data, based on five BT and nine 


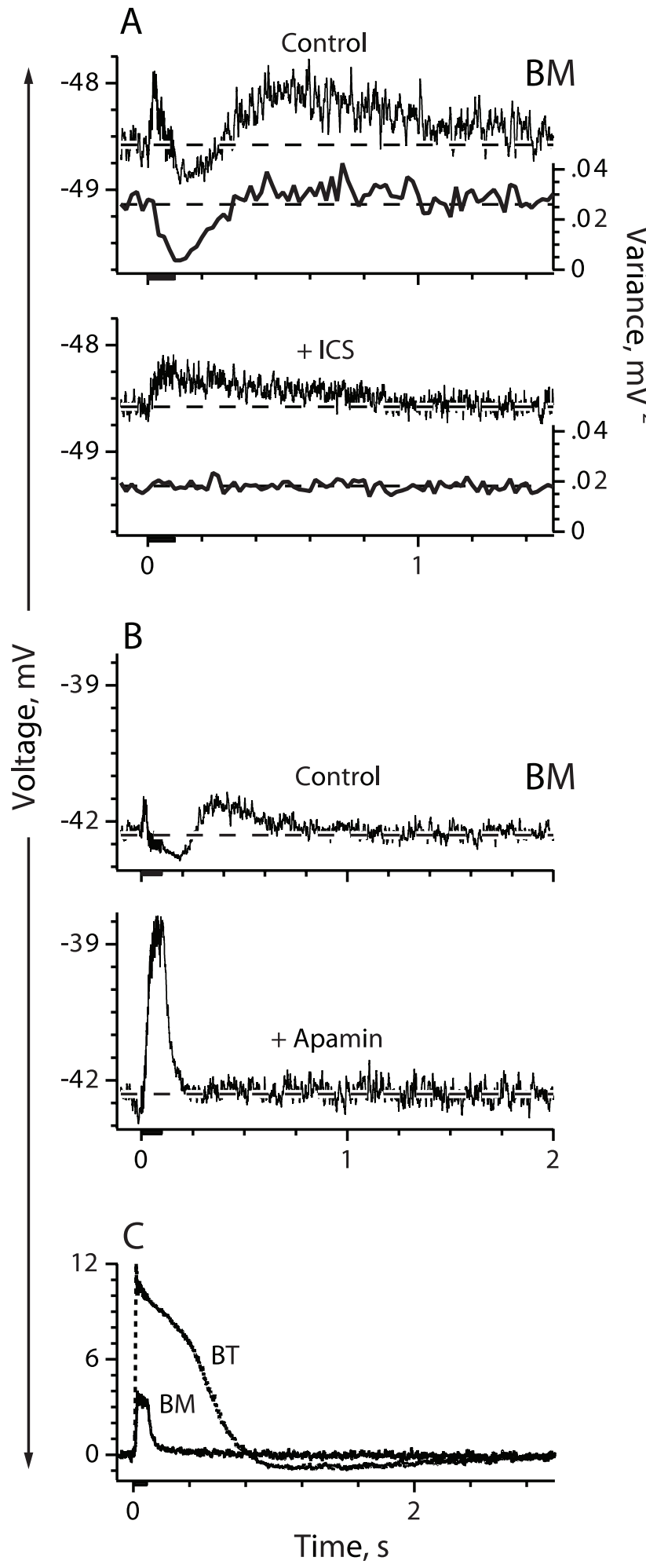

Figure 7. Postinhibitory excitation of BM units depends on the presynaptic inhibition of hair cells evoked by $\alpha 9 / \alpha 10$ activation. $\boldsymbol{A}$, The ensemble mean (top) and variance (bottom) for responses to multiple-shock trains before (Control) and during the presence of the $\alpha 9 / \alpha 10$ blocker $10 \mu \mathrm{m}$ ICS $(+I C S)$. The flat variance trace in the bottom implies that ICS abolishes presynaptic responses including the postinhibitory excitation. The response that remains during ICS is interpreted as a postsynaptic depolarization. B, Apamin $(1 \mu \mathrm{m})$, an SK blocker, converts the biphasic response to multiple-shock trains of a $\mathrm{BM}$ unit into a monophasic depolarization. Both the efferent inhibition and the postinhibitory excitation are abolished. Dashed lines in $\boldsymbol{A}$ and $\boldsymbol{B}$ demark average baseline (prestimulus) values. $\boldsymbol{C}$, The average voltage responses to 20-shock trains for a BT and a BM afferent after conversion to a monophasic depolarizing response by $\mathrm{SCT}$; both the amplitude and duration are smaller in the BM afferent. For other details, see legend to Figure 4.

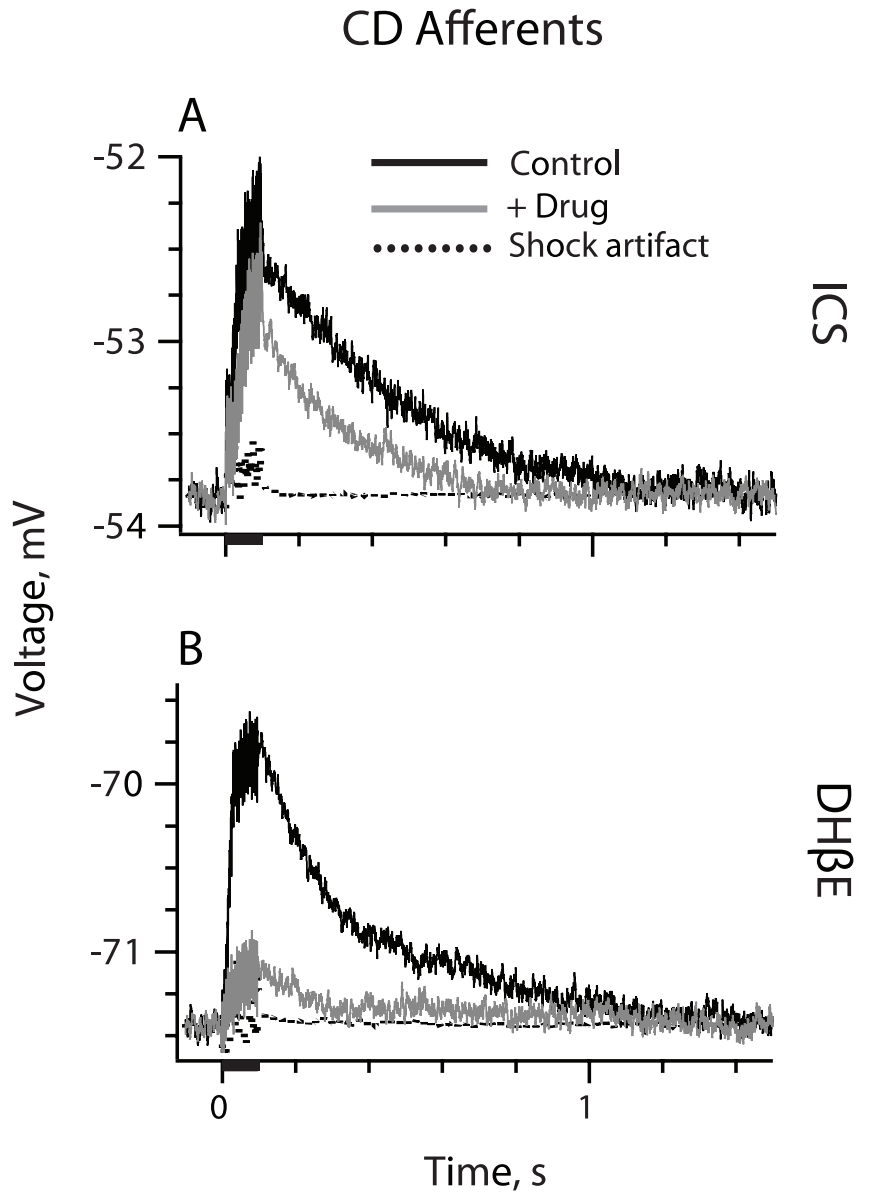

Figure 8. Pharmacology of postsynaptic depolarizing responses in $C D$ afferents can be distinguished from presynaptic responses in $\mathrm{BT} / \mathrm{BM}$ afferents. The effects of ICS and $\mathrm{DH} \beta \mathrm{E}$ on the response of $C D$ afferents to efferent shocks (20 shocks, $200 / \mathrm{s})$. $A$, In a CD afferent, $10 \mu \mathrm{m}$ ICS has only a small effect on the response. $\boldsymbol{B}$, In another $C D$ unit, $300 \mathrm{~nm}$ DH $\beta$ E blocks most of the response. For other details, see legend to Figure 4.

BM units, peak depolarizations in BT units were almost twice as large (mean \pm SEM, $6.12 \pm 1.41$ vs $3.14 \pm 0.53 \mathrm{mV} ; p<0.05$ ), and durations, measured as half-widths, were more than twice as long (324 \pm 54 vs $125 \pm 54 \mathrm{~ms} ; p<0.05)$. Assuming that SK blockers unmask the full extent of the $\mathrm{nAChR}$ response, it would appear that the isolated nicotinic action is weaker in BM units. Despite these differences, the inhibition in the absence of drugs is of similar magnitude in BT and BM units (Table 1), implying that there is a match between the $\mathrm{nAChR}$ and SK responses in each of the two unit groups.

Pharmacological studies also provide suggestions as to the etiology of the postinhibitory excitation characteristic of BM units. As we have already seen, a significant portion of the latter was abolished by CNQX (Fig. $4 B)(n=7)$, implying that it arises presynaptically. In addition, it is severely reduced by $\alpha 9 / \alpha 10$ antagonists (Fig. 7A) $(n=8)$ and by SK channel blockers (Fig. 7B) $(n=6)$, which indicates that its presence depends on the preceding nicotinic-mediated SK hyperpolarization of hair cells.

\section{Postsynaptic components in CD afferents}

Compared with the efferent responses in BT/BM fibers, those in CD units are relatively simple, consisting of an EPSP after single (Fig. 3E) or multiple (Fig. 1I) shocks. Efferent responses in CD afferents are also antagonized by ICS, but the block is partial, typically amounting to $30-40 \%$ with multiple shocks (Fig. $8 \mathrm{~A}$; 

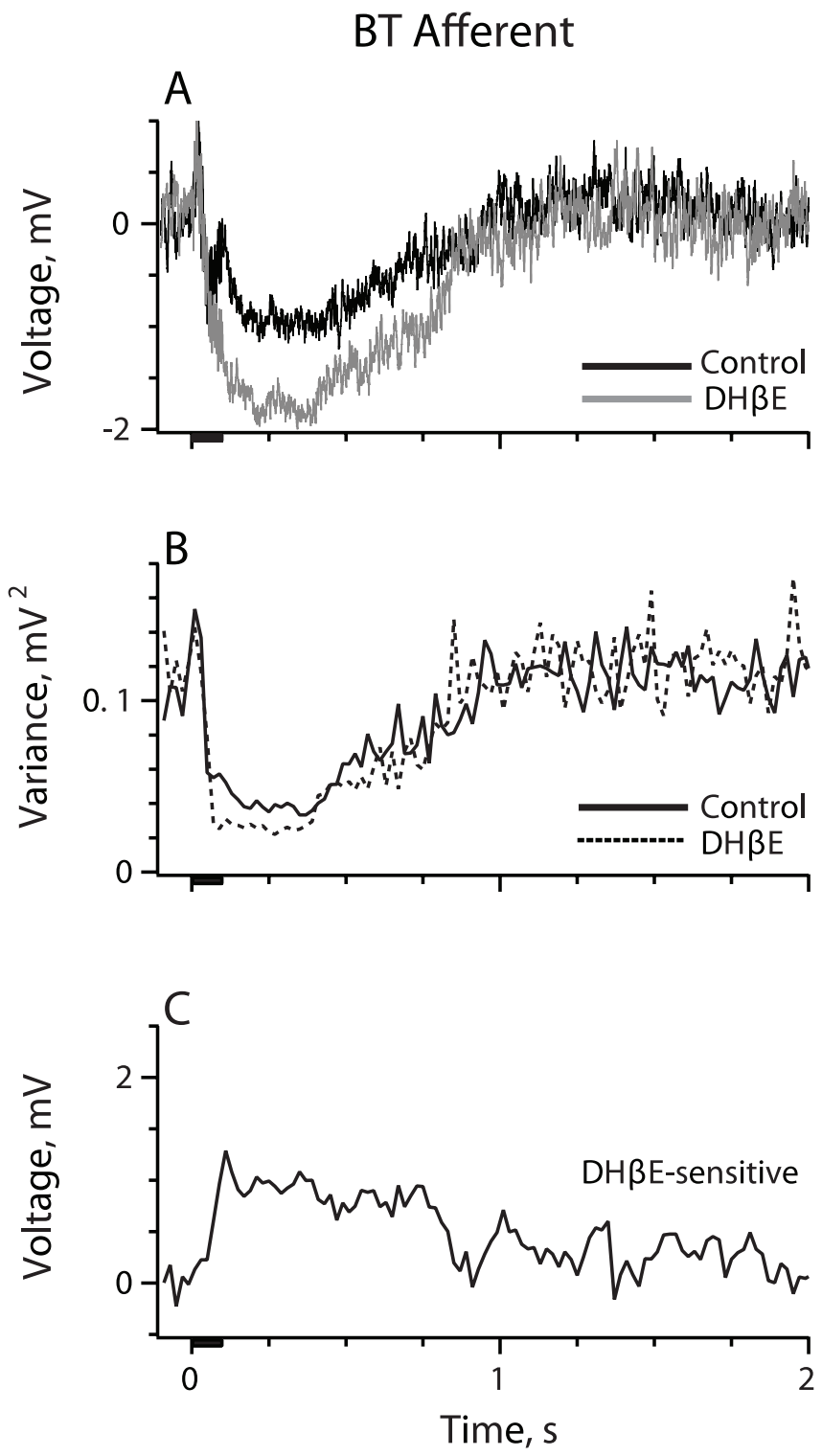

Figure 9. The nicotinic antagonist $\mathrm{DH} \beta \mathrm{E}$ discriminates between presynaptic actions on hair cells and postsynaptic actions on afferents. Ensemble means $(\boldsymbol{A})$ and variances $(\boldsymbol{B})$ in response to 20 shocks at $200 / s$ were recorded before and during the presence of $0.3 \mu \mathrm{m} \mathrm{DH} \beta E$. DH $\beta$ E results in an enhancement of the inhibitory response without a substantial change in the ensemble variance. C, Subtracting the $D H \beta E$ trace from the control trace reveals a $D H \beta E$-sensitive depolarizing component with similar characteristics to the postsynaptic component isolated in BT/BM afferents using CNQX or ICS, as well as the entire efferent response in CD afferents. For other details, see legend to Figure 4.

Table 2). This contrasts with the complete block by ICS of the presynaptic responses in BT/BM units (Figs. 5, 7A; Table 2). Because ICS is a potent competitive antagonist of $\alpha 9 / \alpha 10$ receptors (Rothlin et al., 2003), the results suggest that another receptor is involved in the postsynaptic response in CD units. Consistent with this possibility, the efferent responses in $\mathrm{CD}$ afferents are $70 \%$ blocked by the nicotinic antagonist $\mathrm{DH} \beta \mathrm{E}$ (Fig. $8 \mathrm{~B}$; Table 2 ) at concentrations that do not affect the presynaptic variance responses in BT/BM units (Fig. 9B; Table 2).

Postsynaptic responses in BT/BM units

A postsynaptic depolarization persists in the 20-shock responses of BT/BM units after CNQX abolishes synaptic transmission from hair cells (Fig. 4B). Confirming its postsynaptic origin, the remaining depolarization is not associated with a change in ensemble variance. We were interested in determining whether the remaining depolarization in BT/BM units had a similar pharmacology to that of CD responses. Two observations suggest that this is the case. (1) A depolarization not coupled to a variance change is still present in BT/BM units when presynaptic inhibition is blocked by ICS (Fig. 7A). Group data confirm the conclusion (Table 2): after ICS application, a mean depolarization $(0.24 \pm 0.06 \mathrm{mV})$ is unaccompanied by a variance response $(0.02 \pm 0.04)$. (2) Treatment of BT/BM afferents with a low concentration of $\mathrm{DH} \beta \mathrm{E}(0.3 \mu \mathrm{M})$ results in an enhancement of the inhibitory voltage response (Fig. 9A) without a proportionate change in the ensemble variance (Fig. $9 B$ ). Once again, the conclusion is confirmed in group data (Table 2): there is a large increase in hyperpolarizing voltage (control, $0.00 \pm 0.03 ; \mathrm{DH} \beta \mathrm{E}$, $-0.36 \pm 0.14 \mathrm{mV}$ ) but no change in the variance response measured as a proportionate decrease (control, $-0.44 \pm 0.07$; $\mathrm{DH} \beta \mathrm{E}$, $-0.43 \pm 0.07)$.

A voltage change unaccompanied by a comparable variance change implies that $\mathrm{DH} \beta \mathrm{E}$ at low concentrations affects postsynaptic, but not presynaptic, nicotinic receptors. This is consistent with observations showing that similar concentrations of $\mathrm{DH} \beta \mathrm{E}$ are unable to antagonize $\alpha 9$ nAChRs (Verbitsky et al., 2000). Furthermore, the difference curve (Fig. 9C), obtained by subtracting the $\mathrm{DH} \beta \mathrm{E}$ trace from the control trace in Figure 9A, appears similar to the postsynaptic component isolated in BT/BM afferents after CNQX (Fig. 4B) or ICS application (Fig. 7A).

\section{Ultrastructural studies of efferent terminals in turtle}

Our physiological results indicate that there is a postsynaptic efferent innervation of bouton afferents. Because such an efferent innervation in the turtle was only mentioned in passing (Lysakowski, 1996), its importance could not be evaluated. In our newer material and consistent with our physiological findings, efferent boutons, recognized by their highly vesiculated appearance, terminated both presynaptically on type II hair cells and postsynaptically on afferent processes in all regions of the crista. Both calyces surrounding type I hair cells and afferent boutons terminating on type II hair cells received an efferent innervation.

The two longitudinally sectioned specimens (see Materials and Methods) provided information about the peripheral zone near the torus $\left(\mathrm{PZ}_{\mathrm{T}}\right)$ and near the planum $\left(\mathrm{PZ}_{\mathrm{P}}\right)$, as well as the central zone (Fig. $1 J$ ). In the $\mathrm{PZ}_{\mathrm{T}}, 15$ synapses between efferent boutons and type II hair cells were marked by subsynaptic cisterns (Fig. 10A,B). Efferent synapses, including presynaptic and postsynaptic densities, were found on afferent boutons or on fiber branches as they approached type II hair cells. As illustrated in Figure $10 \mathrm{~A}$, the same efferent bouton could give rise to synapses on both hair cells and bouton fibers. It should be emphasized that efferent synapses on afferent processes were common, amounting to approximately one-third ( 8 of 23) of the efferent synapses encountered in the $\mathrm{PZ}_{\mathrm{T}}$.

The efferent innervation of calyx endings in the $\mathrm{CZ}$ occurred in clusters with two or more highly vesiculated boutons innervating each calyx ending (Fig. 10C,D). There were 19 efferent synapses in the $\mathrm{CZ}$ of our longitudinal material. Three of these were seen on fibers whose destinations could not be determined because they were deep within the neuroepithelium. Eight synapses contacted calyces. Of the eight synapses related to type II hair cells, four were on hair cells and four were on afferent processes. 
No attempt was made to identify the type II hair cells as being innervated by dimorphic or bouton afferents.

Relatively short stretches of the $\mathrm{PZ}_{\mathrm{P}}$ were present in the longitudinal material. Of the five efferent synapses, two were on hair cells and three were on afferent processes. Six efferent synapses were identified in our transverse sections of the $\mathrm{PZ}_{\mathrm{M}}$; all were postsynaptic. One of the longitudinal series grazed the $\mathrm{PZ}_{\mathrm{M}}$; the one efferent synapse found in this location was on a type II hair cell.

Although the sample is small, it shows that afferents innervating type II hair cells in all zones can receive an efferent innervation.

\section{Discussion}

In contrast to auditory organs, we knew very little about the cellular basis of efferent responses in the vestibular labyrinth. One reason is that most intracellular studies of vestibular-nerve fibers were done in the frog (Rossi et al., 1980; Sugai et al., 1991) before the roles of $\alpha 9 / \alpha 10$ (Elgoyhen et al., 1994) and SK channels (Oliver et al., 2000) were established. In addition, the apparent lack of an efferent innervation of afferent fibers in frog vestibular organs (Lysakowski, 1996) precluded a study of postsynaptic efferent responses. The present study was undertaken to correct some of these deficiencies. Our results show that efferent inhibition in a typical vestibular organ is based, as in nonvestibular organs, on the linkage of an $\alpha 9 / \alpha 10$ like receptor and SK. Novel findings were obtained concerning postinhibitory and postsynaptic excitation.

As in the frog studies, we recorded postsynaptically from afferent fibers, which has the advantage that both the quantal activity associated with presynaptic responses and the voltages making up postsynaptic responses can be examined simultaneously. A drawback is that postsynaptic recordings allow us to infer, but not to directly observe, events taking place in hair cells. In addition, we could only record from myelinated axons, because attempts to impale unmyelinated fibers within the neuroepithelium were unsuccessful. Because this necessitated the use of sharp electrodes, activity was recorded in current clamp, which lacks the analytic rigor of voltage-clamp recordings. Nevertheless, such recordings provide a unique opportunity to relate synaptic effects to the efferentevoked modulation of spike discharge.

\section{Hair-cell inhibition is similar in vestibular and nonvestibular organs}

Postsynaptic recordings in frog vestibular organs confirmed that efferent inhibition had a presynaptic origin (Rossi et al., 1980; Bernard et al., 1985; Sugai et al., 1991). Although two components were observed in the efferent-mediated response recorded from frog saccular hair cells, details as to their properties were lacking (Sugai et al., 1992). In our studies, responses to single shocks revealed that a brief, early excitation preceded a more prolonged inhibition. Both components arose presynaptically. Consistent with a sequential activation of $\alpha 9 / \alpha 10$ and SK channels, such as is seen in other hair-cell systems (Oliver et al., 2000), antagonists of $\alpha 9 / \alpha 10$ blocked both components, and SK blockers converted the biphasic response into a prolonged excitation.

By comparing the original biphasic response with the converted response, we estimated that SK channels began opening within $1 \mathrm{~ms}$ of the start of $\mathrm{nAChR}$ activation, which sets limits on the spacing between the nAChR and SK channels. Calculations based on standard diffusion theory (Crank, 1975) indicate that $\mathrm{Ca}^{2+}$ ions could freely diffuse in this time $\sim 1 \mu \mathrm{m}$ in the space delimited by the subsynaptic cisterns of efferent synapses. This suggests that both the nAChRs and SK channels are localized in the same subcisternal space because its dimensions are approximately this magnitude. Because the delay must include the time needed for SK activation (Xia et al., 1998) and the presence of calcium buffers could curtail the diffusion of free $\mathrm{Ca}^{2+}$ (Allbritton et al., 1992), the effective distance between the two channels could be considerably smaller. During the early part of the response, afferent synapses, which are localized at some distance from the cisterns (Lysakowski, 1996), can be affected by electric current flow from efferent synapses but not by $\mathrm{Ca}^{2+}$ diffusion. At 
longer times, $\mathrm{Ca}^{2+}$ can spread to the rest of the hair cell, mostly bound to buffers (Allbritton et al., 1992; Wu et al., 1996). The small amount of free calcium in dynamic equilibrium with the bound form could directly affect afferent neurotransmission and other $\mathrm{Ca}^{2+}$-sensitive processes.

In our experiments, the nicotinic excitation remaining after SK block was much larger than the inhibition seen before the block. This is unlike the results in the mammalian (Glowatzki and Fuchs, 2000; Oliver et al., 2000) or chick (Yuhas and Fuchs, 1999) cochlea, in which the depolarization produced by SK blockers is comparable in magnitude to the preblock hyperpolarization. The different results could be explained were the SK block in other preparations incomplete and/or were nicotinic excitation relatively small. The asymmetry seen in our experiments suggests that the nicotinic and SK components are nearly matched in size. As an alternative, there could be a saturation of the SK component. Although the second explanation cannot be entirely excluded, there is evidence arguing against the two most obvious sources of saturation: a silencing of quantal activity or a saturation of available SK channels. Regardless of the explanation for the asymmetry, it seems reasonable to suppose that the relative sizes of the preblock inhibition and the postblock excitation reflect a balance between the density of nicotinic and SK channels. Other potential contributory factors include calcium buffering (Allbritton et al., 1992; Wu et al., 1996), the role of the cisterns and other internal stores in calcium regulation (Tucker et al., 1996; Lioudyno et al., 2004), and the presence of inward rectifiers (Brichta et al., 2002) that can limit hyperpolarizing responses (Robinson and Siegelbaum, 2003).

Our findings with SK blockers may be relevant to mammals. There is evidence that $\alpha 9 / \alpha 10$ is present in mammalian type II hair cells (Elgoyhen et al., 2001; Cristobal et al., 2005; Luebke et al., 2005), yet inhibition is never seen in mammalian vestibular afferents (Goldberg and Fernandez, 1980; Marlinski et al., 2004). As our results with SK blockers show, an $\alpha 9 / \alpha 10$ receptor not linked to the activation of an SK channel can result in excitation. Were a similar arrangement responsible for the lack of inhibition in mammals, then type II hair cells should, unlike outer hair cells (Dulon et al., 1998; Oliver et al., 2000), lack immunoreactivity to SK.

\section{Postinhibitory excitation may involve a hyperpolarization-activated conductance}

In the turtle, there is a postinhibitory excitation in BM but not in BT units (Brichta and Goldberg, 2000b). A similar phenomenon is seen in frog vestibular-nerve fibers (Sugai et al., 1991) and lateral-line afferents (Dawkins et al., 2005). In our preparation, the excitation arises presynaptically and depends on the preceding inhibition. These observations suggest that hyperpolarization might activate a conductance that would depolarize the hair cell as the hyperpolarization terminates. Three candidates come to mind: a T-type $\mathrm{Ca}^{2+}$ current, an inward rectifier (IRK), and an $I_{\mathrm{H}}$ (HCN) current. A T-type channel has not been seen in hair cells (López et al., 1999; Martini et al., 2000; Bao et al., 2003) (but see Nie et al., 2005). IRK channels are seen in both the turtle crista (Brichta et al., 2002) and frog vestibular organs (Holt and Eatock, 1995; Marcotti et al., 1999), but IRK currents do not show a depolarizing overshoot after a hyperpolarization (Marcotti et al., 1999). $I_{\mathrm{H}}$ is a candidate in the turtle posterior crista because it is only present in type II hair cells that would synapse on BM units (Brichta et al., 2002) and can give rise to both a hyperpolarization sag and a posthyperpolarizing depolarization (Robinson and Siegelbaum, 2003). A possible role in the frog vestibular labyrinth is less clear because an efferent-mediated postinhibitory excitation is seen in both posterior crista and saccular afferents (Sugai et al., 1991). However, although $I_{\mathrm{H}}$ is widely distributed in the saccular macula (Holt and Eatock, 1995), it is not seen in the crista (Marcotti et al., 1999). Some hair cells in the frog crista are excited by efferent stimulations, whereas others are inhibited (Sugai et al., 1991; Holt et al., 2003). Conceivably, a convergence of inhibited and excited hair cells onto single crista afferents could explain the postinhibitory excitation.

\section{Postsynaptic excitation involves nicotinic receptors other than $\alpha 9 / \alpha 10$}

Although a postsynaptic efferent innervation of calyx afferents had been described in the turtle, there had been scanty documentation of a similar innervation of bouton afferents (Lysakowski, 1996). The ultrastructural results in this paper show that bouton afferents receive a robust postsynaptic efferent innervation, which can be related to the postsynaptic depolarization seen in BT/BM fibers.

We found that nicotinic antagonists had different effects on presynaptic and postsynaptic responses. $\alpha 9 / \alpha 10$ antagonists were more potent blockers of presynaptic responses, whereas $\mathrm{DH} \beta \mathrm{E}$ had a more profound effect on postsynaptic actions. Our pharmacological observations could be explained by the combined presence postsynaptically of $\alpha 9 / \alpha 10$ and another nicotinic receptor. A possible postsynaptic localization of $\alpha 9 / \alpha 10 \mathrm{nAChRs}$ is currently controversial. Antibodies to $\alpha 9$ labeled calyces and most Scarpa's ganglion cells in rodents (Luebke et al., 2005). Consistent with this observation, calyx endings were labeled with $\alpha$-BTX (Ishiyama et al., 1995; Wackym et al., 1995; Dailey et al., 2000). Conversely, in situ hybridization studies, although failing to detect either $\alpha 9$ (Hiel et al., 1996) or $\alpha 10$ (Elgoyhen et al., 2001) mRNA in Scarpa's ganglion cells, did find mRNA expression for other nAChR subunits (Wackym et al., 1995; Hiel et al., 1996; Anderson et al., 1997). Our data indicate the postsynaptic presence of another nicotinic receptor, possibly in addition to $\alpha 9 / \alpha 10$. An attractive candidate for the other nicotinic receptor is $\alpha 4 / \beta 2$ given that it is sensitive to $\mathrm{DH} \beta \mathrm{E}$ (Holladay et al., 1997; Karadsheh et al., 2004) and its mRNA is expressed in vestibular ganglia (Wackym et al., 1995; Zoli et al., 1995).

\section{References}

Allbritton NL, Meyer T, Stryer L (1992) Range of messenger action of calcium ion and inositol 1, 4, 5-trisphosphate. Science 258:1812-1815.

Anderson AD, Troyanovskaya M, Wackym PA (1997) Differential expression of $\alpha 2-7, \alpha 9$ and $\beta 2-4$ nicotinic acetylcholine receptor subunit mRNA in the vestibular end-organs and Scarpa's ganglia of the rat. Brain Res 778:409-413.

Art JJ, Crawford AC, Fettiplace R, Fuchs PA (1985) Efferent modulation of hair cell tuning in the cochlea of the turtle. J Physiol (Lond) 360:397-421.

Bao H, Wong WH, Goldberg JM, Eatock RA (2003) Voltage-gated calcium channel currents in type I and type II hair cells isolated from the rat crista. J Neurophysiol 90:155-164.

Bernard C, Cochran SL, Precht W (1985) Presynaptic actions of cholinergic agents upon the hair cell-afferent fiber synapses in the vestibular labyrinth of the frog. Brain Res 338:225-236.

Boyle R, Highstein SM (1990) Efferent vestibular system in the toadfish: action upon horizontal semicircular canal afferents. J Neurosci 10:1570-1582.

Brichta AM, Goldberg JM (2000a) Morphological identification of physiologically characterized afferents innervating the turtle posterior crista. J Neurophysiol 83:1202-1223.

Brichta AM, Goldberg JM (2000b) Responses to efferent activation and excitatory response-intensity relations of turtle posterior-crista afferents. J Neurophysiol 83:1224-1242.

Brichta AM, Peterson EH (1994) Functional architecture of vestibular pri- 
mary afferents from the posterior semicircular canal of a turtle, Pseudemys (Trachemys) scripta elegans. J Comp Neurol 344:481-507.

Brichta AM, Aubert A, Eatock RA, Goldberg JM (2002) Regional analysis of whole cell currents from hair cells of the turtle posterior crista. J Neurophysiol 88:3259-3278.

Crank J (1975) The mathematics of diffusion, Ed 2. Oxford: Oxford UP.

Cristobal R, Wackym PA, Cioffi JA, Erbe CB, Roche JP, Popper P (2005) Assessment of differential gene expression in vestibular epithelial cell types using microarray analysis. Brain Res Mol Brain Res 133:19-36.

Dailey SH, Wackym PA, Brichta AM, Gannon PJ, Popper P (2000) Topographic distribution of nicotinic acetylcholine receptors in the cristae of a turtle. Hear Res 141:51-56.

Dawkins R, Keller SL, Sewell WF (2005) Pharmacology of acetylcholinemediated cell signaling in the lateral line organ following efferent stimulation. J Neurophysiol 93:2541-2551.

Dickman JD, Correia MJ (1993) Bilateral communication between vestibular labyrinths in pigeons. Neuroscience 57:1097-1108.

Dulon D, Luo L, Zhang C, Ryan AF (1998) Expression of small-conductance calcium-activated potassium channels (SK) in outer hair cells of the rat cochlea. Eur J Neurosci 10:907-915.

Elgoyhen AB, Johnson DS, Boulter J, Vetter DE, Heinemann S (1994) $\alpha 9$ : an acetylcholine receptor with novel pharmacological properties expressed in rat cochlear hair cells. Cell 79:705-715.

Elgoyhen AB, Vetter DE, Katz E, Rothlin CV, Heinemann SF, Boulter J (2001) $\alpha 10$ : a determinant of nicotinic cholinergic receptor function in mammalian vestibular and cochlear mechanosensory hair cells. Proc Natl Acad Sci USA 98:3501-3506.

Fayyazuddin A, Brichta AM, Art JJ (1991) Organization of eighth nerve efferents in the turtle, Pseudemys scripta. Soc Neurosci Abstr 17:312.

Fuchs PA, Murrow BW (1992) Cholinergic inhibition of short (outer) hair cells of the chick's cochlea. J Neurosci 12:800-809.

Furukawa T (1981) Effects of efferent stimulation on the saccule of goldfish. J Physiol (Lond) 315:203-215.

Glowatzki E, Fuchs PA (2000) Cholinergic synaptic inhibition of inner hair cells in the neonatal mammalian cochlea. Science 288:2366-2368.

Goldberg JM, Fernandez C (1980) Efferent vestibular system in the squirrel monkey: anatomical location and influence on afferent activity. J Neurophysiol 43:986-1025.

Goldberg JM, Brichta AM, Wackym PW (1999) Efferent vestibular system: anatomy, physiology and neurochemistry. In: Neurochemistry of the vestibular system (Anderson JH, Beitz AJ, eds), pp 61-94. Boca Raton, FL: CRC.

Gomez-Casati ME, Fuchs PA, Elgoyhen AB, Katz E (2005) Biophysical and pharmacological characterization of nicotinic cholinergic receptors in rat cochlear inner hair cells. J Physiol (Lond) 566:103-118.

Guth PS, Perin P, Norris CH, Valli P (1998) The vestibular hair cells: posttransductional signal processing. Prog Neurobiol 54:193-247.

Hiel H, Elgoyhen AB, Drescher DG, Morley BJ (1996) Expression of nicotinic acetylcholine receptor mRNA in the adult rat peripheral vestibular system. Brain Res 738:347-352.

Holladay MW, Dart MJ, Lynch JK (1997) Neuronal nicotinic acetylcholine receptors as targets for drug discovery. J Med Chem 40:4169-4194.

Holt JC, Lioudyno M, Athas G, Garcia MM, Perin P, Guth PS (2001) The effect of proteolytic enzymes on the $\alpha 9$-nicotinic receptor-mediated response in isolated frog vestibular hair cells. Hear Res 152:25-42.

Holt JC, Lioudyno M, Guth PS (2003) A pharmacologically distinct nicotinic ACh receptor is found in a subset of frog semicircular canal hair cells. J Neurophysiol 90:525-536.

Holt JC, Xue JT, Brichta AM, Goldberg JM (2006) Transmission between type II hair cells and bouton afferents in the turtle posterior crista. J Neurophysiol 95:428-452.

Holt JR, Eatock RA (1995) Inwardly rectifying currents of saccular hair cells from the leopard frog. J Neurophysiol 73:1484-1502.

Ishiyama A, Lopez I, Wackym PA (1995) Distribution of efferent cholinergic terminals and alpha-bungarotoxin binding to putative nicotinic acetylcholine receptors in the human vestibular end-organs. Laryngoscope 105:1167-1172.

Karadsheh MS, Shah MS, Tang X, Macdonald RL, Stitzel JA (2004) Functional characterization of mouse $\alpha 4 \beta 2$ nicotinic acetylcholine receptors stably expressed in HEK293T cells. J Neurochem 91:1138-1150.

Lioudyno M, Hiel H, Kong JH, Katz E, Waldman E, Parameshwaran-Iyer S,
Glowatzki E, Fuchs PA (2004) A "synaptoplasmic cistern" mediates rapid inhibition of cochlear hair cells. J Neurosci 24:1160-1164.

Locke R, Vautrin J, Highstein SM (1999) Miniature EPSPs and sensory encoding in the primary afferents of the vestibular lagena of the toadfish, Opsanus tau. Ann NY Acad Sci 871:135-150.

López I, Ishiyama G, Ishiyama A, Jen JC, Liu F, Baloh RW (1999) Differential subcellular immunolocalization of voltage-gated calcium channel $\alpha 1$ subunits in the chinchilla cristae ampullaris. Neuroscience 92:773-782.

Luebke AE, Maroni PD, Guth SM, Lysakowski A (2005) Alpha-9 nicotinic acetylcholine receptor subunit immunoreactivity in the rodent vestibular labyrinth. J Comp Neurol 492:323-333.

Lysakowski A (1996) Synaptic organization of the crista ampullaris in vertebrates. Ann NY Acad Sci 781:164-182.

Lysakowski A, Goldberg JM (1997) A regional ultrastructural analysis of the cellular and synaptic architecture in the chinchilla cristae ampullares. J Comp Neurol 389:419-443.

Lysakowski A, Goldberg JM (2004) Morphophysiology of the vestibular periphery. In: The vestibular system (Highstein SM, Popper A, Fay RR, eds), pp 57-152, New York: Springer.

Marcotti W, Russo G, Prigioni I (1999) Position-dependent expression of inwardly rectifying $\mathrm{K}^{+}$currents by hair cells of frog semicircular canals. NeuroReport 10:601-606.

Marlinski V, Plotnik M, Goldberg JM (2004) Efferent actions in the chinchilla vestibular labyrinth. J Assoc Res Otolaryngol 5:126-143.

Martini M, Rossi ML, Rubbini G, Rispoli G (2000) Calcium currents in hair cells isolated from semicircular canals of the frog. Biophys J $78: 1240-1254$.

Meredith GE (1988) Comparative view of the central organization of afferent and efferent circuitry for the inner ear. Acta Biol Hung 39:229-249.

Neher E, Sakaba T (2003) Combining deconvolution and fluctuation analysis to determine quantal parameters and release rates. J Neurosci Methods 130:143-157.

Nenov AP, Norris C, Bobbin RP (1996) Acetylcholine response in guinea pig outer hair cells. II. Activation of a small conductance $\mathrm{Ca}^{2+}$-activated $\mathrm{K}^{+}$channel. Hear Res 101:149-172.

Nie L, Hoi TT, Dinglasan JN, Yamoah EN (2005) Molecular cloning of inner ear-specific T-type $\mathrm{Ca}^{2+}$ channels in the mouse. 29th Midwinter Meeting for The Association for Research in Otolaryngology Abstract 748. Retrieved December 13, 2006 from http://www.aro.org/archives/ 2005/2005_748.html.

Oliver D, Klocker N, Schuck J, Baukrowitz T, Ruppersberg JP, Fakler B (2000) Gating of $\mathrm{Ca}^{2+}$-activated $\mathrm{K}^{+}$channels controls fast inhibitory synaptic transmission at auditory outer hair cells. Neuron 26:595-601.

Rice SO (1944) Mathematical analysis of random noise. Bell Sys Tech J 23:282-332.

Robinson RB, Siegelbaum SA (2003) Hyperpolarization-activated cation currents: from molecules to physiological function. Annu Rev Physiol 65:453-480.

Rossi ML, Martini M (1991) Efferent control of posterior canal afferent receptor discharge in the frog labyrinth. Brain Res 555:123-134.

Rossi ML, Prigioni I, Valli P, Casella C (1980) Activation of the efferent system in the isolated frog labyrinth: effects on the afferent EPSPs and spike discharge recorded from single fibres of the posterior nerve. Brain Res 185:125-137.

Rothlin CV, Lioudyno MI, Silbering AF, Plazas PV, Casati ME, Katz E, Guth PS, Elgoyhen AB (2003) Direct interaction of serotonin type 3 receptor ligands with recombinant and native $\alpha 9 \alpha 10$-containing nicotinic cholinergic receptors. Mol Pharmacol 63:1067-1074.

Russell IJ (1968) Influence of efferent fibres on a receptor. Nature 219:177-178.

Stocker M, Hirzel K, D'hoedt D, Pedarzani P (2004) Matching molecules to function: neuronal $\mathrm{Ca}^{2+}$-activated $\mathrm{K}^{+}$channels and afterhyperpolarizations. Toxicon 43:933-949.

Sugai T, Sugitani M, Ooyama H (1991) Effects of activation of the divergent efferent fibers on the spontaneous activity of vestibular afferent fibers in the toad. Jpn J Physiol 41:217-232.

Sugai T, Yano J, Sugitani M, Ooyama H (1992) Actions of cholinergic agonists and antagonists on the efferent synapse in the frog sacculus. Hear Res 61:56-64.

Tucker T, Art JJ, Fettiplace R (1996) Routes of calcium entry and extrusion in turtle hair cells. Ann NY Acad Sci 781:123-137. 
Verbitsky M, Rothlin CV, Katz E, Elgoyhen AB (2000) Mixed nicotinicmuscarinic properties of the $\alpha 9$ nicotinic cholinergic receptor. Neuropharmacology 39:2515-2524.

Wackym PA, Popper P, Lopez I, Ishiyama A, Micevych PE (1995) Expression of $\alpha 4$ and $\beta 2$ nicotinic acetylcholine receptor subunit mRNA and localization of alpha-bungarotoxin binding proteins in the rat vestibular periphery. Cell Biol Int 19:291-300.

Warr WB, Guinan JJ (1979) Efferent innervation in the organ or Corti: two separate systems. Brain Res 173:660-686.

Weisstaub N, Vetter DE, Elgoyhen AB, Katz E (2002) The $\alpha 9 \alpha 10$ nicotinic acetylcholine receptor is permeable to and is modulated by divalent cations. Hear Res 167:122-135.

Wu YC, Tucker T, Fettiplace R (1996) A theoretical study of calcium microdomains in turtle hair cells. Biophys J 71:2256-2275.
Xia XM, Fakler B, Rivard A, Wayman G, Johnson-Pais T, Keen JE, Ishii T, Hirschberg B, Bond CT, Lutsenko S, Maylie J, Adelman JP (1998) Mechanism of calcium gating in small-conductance calcium-activated potassium channels. Nature 395:503-507.

Yamashita M (1986) Monosynaptic connexions of low threshold muscle afferents with hindlimb motoneurones in the turtle spinal cord. Exp Brain Res 63:519-529.

Yuhas WA, Fuchs PA (1999) Apamin-sensitive, small-conductance, calcium-activated potassium channels mediate cholinergic inhibition of chick auditory hair cells. J Comp Physiol A Neuroethol Sens Neural Behav Physiol 185:455-462.

Zoli M, Le Novere N, Hill JA, Changeux JP (1995) Developmental regulation of nicotinic ACh receptor subunit mRNAs in the rat central and peripheral nervous systems. J Neurosci 15:1912-1939. 